\title{
An evolutionary modelling approach to predicting stress-strain behaviour of saturated granular soils
}

\begin{abstract}
Purpose - To develop a unified framework for modelling triaxial deviator stress - axial strain and volumetric strain - axial strain behaviour of granular soils with the ability to predict the entire stress paths, incrementally, point by point, in deviator stress versus axial strain $\left(q: \varepsilon_{a}\right)$, and volumetric strain versus axial strain $\left(\varepsilon_{v}: \varepsilon_{a}\right)$ spaces using an evolutionary-based technique based on a comprehensive set of data directly measured from triaxial tests without preprocessing. 177 triaxial test results acquired from literature were used to develop and validate the models. Models aimed not only to be capable of capturing and generalising the complicated behaviour of soils but also to explicitly remain consistent with expert knowledge available for such behaviour.
\end{abstract}

Methodology - Evolutionary polynomial regression was used to develop models to predict stress-axial strain and volumetric strain - axial strain behaviour of granular soils. EPR integrates numerical and symbolic regression to perform evolutionary polynomial regression. The strategy uses polynomial structures to take advantage of favourable mathematical properties. EPR is a two-stage technique for constructing symbolic models. It initially implements evolutionary search for exponents of polynomial expressions using a genetic algorithm (GA) engine to find the best form of function structure, secondly it performs a least squares regression to find adjustable parameters, for each combination of inputs (terms in the polynomial structure).

Findings - EPR-based models were capable of generalizing the training to predict the behaviour of granular soils under conditions that have not been previously seen by EPR in the training stage. It was shown that the proposed EPR models outperformed ANN and provided 
closer predictions to the experimental data cases. The entire stress paths for the shearing behaviour of granular soils using developed model predictions were created with very good accuracy despite error accumulation. Parametric study results revealed the consistency of developed model predictions, considering roles of various contributing parameters, with physical and engineering understandings of the shearing behaviour of granular soils.

Originality/value - In this paper, an evolutionary-based data-mining method was implemented to develop a novel unified framework to model the complicated stress-strain behaviour of saturated granular soils. The proposed methodology overcomes the drawbacks of artificial neural network-based models with black box nature by developing accurate, explicit, structured and user-friendly polynomial models, and enabling the expert user to obtain a clear understanding of the system.

\section{Introduction}

The shear strength of cohesionless soil such as sand and gravel under varying drainage conditions has been a topic of significant interest for the last four decades. Many research works have contributed significantly to understanding of the important factors that control the shear strength behaviour of sand and gravel in drained conditions, including large number of experiments e.g. triaxial tests conducted with results published in the literature. There has been a lot of interest in the research community to model the shear stress and volume change behaviour of cohesionless soil and because of its well defined conditions of stress and strain on the cylindrical specimens, many of the models developed to date are predominantly based on triaxial compression test data. The majority of the past research effort has been devoted to modelling of soil behaviour using the elasticity/plasticity based approach with some success (Rowe and Barden 1964). Ellis et al (1995) suggested a feed-back neural network model for 
representing shearing behaviour of sand in undrained conditions. Following Ellis et al (1995) work, Penumadu and Zhao (1999) also developed a neural network based models for triaxial compression behaviour of sand and gravel. The results presented in their paper, representing the deviator stress and volume change behaviour of varying types of sand and gravel for drained conditions, suggested some improvements compared to Ellis et all (1995) work (Penumadu and Zhao 1999): (i) developing a suitable strain increment value in the feed-back process; (ii) avoiding errors associated with over-training during the training phase; (iii) implementing a procedure for obtaining optimal size of the hidden layer; and (iv) modelling triaxial compression behaviour of both sand and gravel under drained conditions. In this research work the evolutionary polynomial regression (EPR) is implemented to develop structured and transparent models in the form of polynomial equations to represent the shear strength and volume change behaviour of saturated granular geomaterials. EPR models have the capability of capturing and representing the behaviour of materials in easily understandable form for the user. A clear insight into the role of different contributing parameters is also given to the users by the developed models helping them better understand the physics of complicated behaviour of materials and systems.

A comprehensive set of data from literature was collected and used to develop and validate the EPR models for stress-strain and volume change behaviour of cohesionless soils.

Data preparation, model development procedure and also the merits and advantages of the proposed technique will be discussed in detail in following sections in this paper. Comparisons are also made between EPR model predictions and the experimental data as well as results from artificial neural network model predictions presented by Penumadu and Zhao (1999). Sensitivity analysis outcomes and the relevant discussions are also presented in next coming parts of paper. 


\section{Evolutionary Polynomial Regression}

Evolutionary polynomial regression EPR integrates numerical and symbolic regression to perform evolutionary polynomial regression. The strategy uses polynomial structures to take advantage of their favourable mathematical properties. The key idea behind the EPR is to use evolutionary search for exponents of polynomial expressions by means of a genetic algorithm (GA) engine. This allows ( $i$ ) easy computational implementation of the algorithm, (ii) efficient search for an explicit expression, and (iii) improved control of the complexity of the expression generated (Giustolisi and Savic 2006). EPR is a data-driven method based on evolutionary computing, aimed to search for polynomial structures representing a system. A physical system, having an output $\mathrm{y}$, dependent on a set of inputs $\mathrm{X}$ and parameters $\theta$, can be mathematically formulated as:

$$
y=F(\mathbf{X}, \boldsymbol{\theta})
$$

where $\mathrm{F}$ is a function in an $\mathrm{m}$-dimensional space and $\mathrm{m}$ is the number of inputs. To avoid the problem of mathematical expressions growing rapidly in length with time, in EPR the evolutionary procedure is conducted in the way that it searches for the exponents of a polynomial function with a fixed maximum number of terms. During one execution it returns a number of expressions with increasing numbers of terms up to a limit set by the user, to allow the optimum number of terms to be selected. The general form of expression used in EPR can be presented as (Giustolisi and Savic 2006):

$$
y=\sum_{j=1}^{m} F\left(\mathbf{X}, f(\mathbf{X}), a_{j}\right)+a_{0}
$$

where $y$ is the estimated vector of output of the process; $a_{j}$ is a constant; $F$ is a function constructed by the process; $\mathrm{X}$ is the matrix of input variables; $\mathrm{f}$ is a function defined by the user (it may be natural logarithmic, exponential, tangent hyperbolic, etc.); and $\mathrm{m}$ is the number of 
terms of the target expression. The first step in identification of the model structure is to transfer Equation 2 into the following vector form:

$$
Y_{N \times 1}(\theta, Z)=\left[\begin{array}{ll}
I_{N \times 1} & Z_{N \times m}^{j}
\end{array}\right] \times\left[\begin{array}{llll}
a_{0} & a_{1} & \ldots & a_{m}
\end{array}\right]^{T}=Z_{N \times d} \times \theta_{d \times 1}^{T}
$$

where $Y_{N \times 1}(\theta, Z)$ is the least squares estimate vector of the $N$ target values; $\theta_{d \times 1}$ is the vector of $d=m+1$ parameters $a_{j}$ and $a_{0}\left(\theta^{T}\right.$ is the transposed vector); and $Z_{N \times d}$ is a matrix formed by $I$ (unitary vector) for bias $a_{0}$, and $m$ vectors of variables $Z_{j}$. For a fixed $j$, the variables $Z_{j}$ are $a$ product of the independent predictor vectors of inputs, $X=\left\langle X_{1} X_{2} \ldots X_{k}\right\rangle$ (where " $k$ " is the number of independent predictor variables - inputs). $Z_{\mathrm{j}}$ is a transformed variable which is a function of the independent predictor variables, inputs, $X_{1} X_{2} \ldots X_{k}$, evaluated at the $j$ th data point (Giustolisi and Savic 2006).

In general, EPR is a two-stage technique for constructing symbolic models. Initially, using standard genetic algorithm (GA), it searches for the best form of the function structure, i.e. a combination of vectors of independent inputs, $X_{s}=1: k$ (where " $k$ " is the number of independent predictor variables - inputs), and secondly it performs a least squares regression to find the adjustable parameters, $\theta$, for each combination of inputs. In this way a global search algorithm is implemented for both the best set of input combinations and related exponents simultaneously, according to the user-defined cost function (Giustolisi and Savic 2006). The adjustable parameters, $\mathrm{a}_{\mathrm{j}}$, are evaluated by means of the linear least squares (LS) method based on minimization of the sum of squared errors (SSE) as the cost function. The SSE function which is used to guide the search process towards the best fit model is as follows:

$$
\mathbf{S S E}=\frac{\sum_{i=1}^{N}\left(y_{a}-y_{p}\right)^{2}}{N}
$$

where $y_{a}$ and $y_{p}$ are the target experimental and the model prediction values respectively. The global search for the best form of the EPR equation is performed by means of a standard GA 
over the values in the user defined vector of exponents. The GA operates based on Darwinian evolution which begins with random creation of an initial population of solutions. Each parameter set in the population represents the individual's chromosomes. Each individual is assigned a fitness based on how well it performs in its environment. Through crossover and mutation operations, with the probabilities $\mathrm{Pc}$ and Pm respectively, the next generation is created. Fit individuals are selected for mating, whereas weak individuals die off. The mated parents create a child (offspring) with a chromosome set which is a mix of parents' chromosomes. In EPR integer GA coding with single point crossover is used to determine the location of the candidate exponents.

The EPR process stops when the termination criterion, which can be either the maximum number of generations, the maximum number of terms in the target mathematical expression or a particular allowable error, is satisfied. A typical flow diagram for the EPR procedure is illustrated in Figure 1.

\section{Database and the parameters involved in development of the models}

Previous experimental research has shown that the important factors that govern the behaviour of cohesionless soils (sand and gravel) are their mineralogy, particle shape, particle size and its distribution, void ratio and also the effective confining stress level (Penumadu and Zhao 1999). The experimental database from a large number of contributions from literature (Table 1) was used to develop the models in this research. The database included the effects of the above mentioned factors systematically in a comprehensive manner using a large number of drained triaxial compression tests.

The objective was to develop EPR-based models to represent the deviator stress-axial strain, and volumetric strain-axial strain relationships for granular soils with varying mineralogy, particle shape, uniformity coefficient, coefficient of curvature, effective particle size, void ratio, and effective confining pressure. 
Data from a total of 177 triaxial compression tests were obtained from literature. Using the approach proposed by Hardin (1985), the mineralogy and grain shape were quantified in the database using crushing hardness, and average particle shape factor. The crushing hardness, $\boldsymbol{h}$ (a mineralogy factor) is approximately equal to the scratch hardness as defined by Moh's Scale. It takes a value of 7, 6, and 3 for quartz, feldspar, and calcite respectively. The shape factor $\left(\boldsymbol{n}_{\mathbf{s}}\right)$ defines the degree of angularity, and is equal to: 25 for angular, 20 for sub-angular, 17 for sub-round, and 15 for round shape (Penumadu and Zhao 1999).

\section{Data preparation}

From among 177 triaxial test results, $138(80 \%)$ was used for model construction and the remaining 39 (20\%), kept unseen to EPR during the model development procedure, was implemented to validate the developed models. It was checked to make sure that all parameter values in the testing data sets were within the range of data chosen to be used for training EPR and developing the models to avoid extrapolation.

To select the most robust combination of the training and testing data, a statistical analysis was performed on the input and output parameter values (Table 2) of several randomly selected training and validation data combinations. The aim of the analysis was to ensure that the statistical properties of the data in each of the subsets (training or testing) were as close to the other as possible and thus represented the same statistical population. The mean and standard deviation values were calculated for every single contributing parameter and for the training and testing datasets for every randomly considered combination and the combination for which these statistical values were the closest in the training and testing data sets was chosen to be used in training and testing stages in the EPR model development process (Hussain M. S. 2015, Ahangar Asr and Javadi 2016). 


\section{EPR Procedure}

Before starting the evolutionary procedure, a number of constraints can be implemented to control the structure of the models to be constructed, in terms of type of functions used, number of terms, range of exponents, number of generations etc. It can be seen that there is a potential to achieve different models for a particular problem which enables the user to gain additional information (Javadi and Rezania 2009). Applying the EPR procedure, the evolutionary process starts from a constant mean of output values. By increasing the number of evolutions it gradually picks up the different participating parameters in order to form equations representing the relationship between contributing and output parameters. Each model is trained using the training data and tested using the testing data. The level of accuracy at each stage is evaluated based on the coefficient of determination (COD) i.e. the fitness function:

$$
\mathbf{C O D}=1-\frac{\sum_{N}\left(\mathbf{Y}_{a}-\mathbf{Y}_{p}\right)^{2}}{\sum_{N}\left(\mathbf{Y}_{a}-\frac{1}{N} \sum_{N} \mathbf{Y}_{a}\right)^{2}}
$$

where $\mathbf{Y}_{a}$ is the actual output value; $\mathbf{Y}_{p}$ is the EPR predicted value and $N$ is the number of data points on which the COD is computed. If the model fitness is not acceptable or the other termination criteria (in terms of maximum number of generations and maximum number of terms) are not satisfied, the current model should go through another evolution in order to obtain a new model.

\section{Developing the EPR models}

A typical scheme to train most of the neural network based material models for soils includes an input set providing the network with information relating to the current state units (e.g., current stresses and strains) and then a forward pass through the network yields the prediction of the next expected state of stress or strain relevant to an input strain or stress increment ( (Ghaboussi, et al. 1998); (Penumadu and Zhao 1999)). Due to the incremental nature of soil 
stress-strain modelling in practical applications, the same scheme was also used in this research to model the behaviour of granular materials.

The EPR models had 11 input parameters (Table 2). $D_{50}, C_{u}, C_{c}, h, n_{s,} e$ and $\sigma_{3}$ represented the initial conditions of the soil specimens, but the other three parameters, namely axial strain, volumetric strain, and deviator stress were updated incrementally during the training and testing based on the outputs from the previous increment of the axial strain. The output parameters were the deviator stress and the volumetric strain corresponding to the end of the incremental step and were calculated using the two EPR models.

The training of the EPR resulted in development of more than one equation for deviator stress. From among the EPR outcome equations, 2 did not include the effect of all contributing parameters meaning that that the introduced parameters to EPR were not appearing in the resulted models. From the remaining equations with all the desired parameters involved, the most appropriate and efficient one based on the: (i) model performance (fitness); (ii) complexity; and also (iii) the sensitivity analysis results was chosen as the final model. A similar procedure was also followed to create and choose the best equation (model) for the volumetric behaviour. Equations 6 and 7 represent the EPR models for deviator stress and volume strain respectively.

$$
\begin{aligned}
q_{i+1}=-\frac{1.3 E(-5) C_{c}^{3} \varepsilon_{a} \Delta \varepsilon_{a} \sigma_{3} \varepsilon_{v_{i}}}{D_{50}^{2} C_{u}^{3}}+\frac{1.1 E(-4) C_{c}^{3} h^{3} n_{s}^{3} \varepsilon_{a} \Delta \varepsilon_{a}}{D_{50} C_{u} e^{3} q_{i}}+\frac{0.1 n_{s}^{3} \Delta \varepsilon_{a}}{C_{u} C_{c}^{2} h e^{2}}+\frac{0.2 C_{c} h \Delta \varepsilon_{a} \sigma_{3}}{n_{s}} \\
+\frac{60.9 C_{u} \Delta \varepsilon_{a} \sigma_{3} \varepsilon_{v_{i}}}{C_{c}^{2} n_{s}^{2} q_{i}}+\frac{2.3 E(-9) C_{u}^{3} e^{3} \sigma_{3}^{3} \varepsilon_{v_{i}}}{C_{c}^{2} h^{2} n_{s}^{3} \Delta \varepsilon_{a}^{2}}+\frac{2.3 E(-4) C_{u}^{3} \Delta \varepsilon_{a}^{2} \sigma_{3}^{2} \varepsilon_{v_{i}}}{h^{2} n_{s}^{2} q_{i}} \\
+\frac{5.9 E(-4) D_{50} C_{c}^{3} e^{2} \sigma_{3}^{3} \varepsilon_{v_{i}}^{2}}{C_{u}^{2} h n_{s}^{3} \Delta \varepsilon_{a} q_{i}}+\frac{8.3 E(-9) D_{50} h^{3} \varepsilon_{a} \Delta \varepsilon_{a}^{2} \sigma_{3} q_{i}}{C_{u} n_{s}} \\
-8.3 E(-4) C_{c} h \varepsilon_{a} \Delta \varepsilon_{a} \sigma_{3}+0.03 \sigma_{3}+q_{i}
\end{aligned}
$$




$$
\begin{gathered}
\varepsilon_{v_{i+1}}=-\frac{0.1 \varepsilon_{a}}{D_{50} C_{c}^{2} h^{2} n_{s} \Delta \varepsilon_{a}}+\frac{0.03 h}{D_{50} C_{c} n_{s}}-\frac{1.6 E(-7) e \varepsilon_{a} \sigma_{3} \varepsilon_{v_{i}}}{C_{u}^{3} C_{c}^{2} h}-\frac{3.6 E(-9) h n_{s} \sigma_{3}}{C_{u} C_{c}^{3} e \Delta \varepsilon_{a}}-\frac{3 E(-5)}{C_{u} C_{c} \Delta \varepsilon_{a}^{2}} \\
+\frac{0.13 \varepsilon_{a} \Delta \varepsilon_{a}-1.5 E(-4) D_{50} C_{u}^{2} C_{c} n_{s} \Delta \varepsilon_{a}^{3} h}{h^{2}}-1.6 \Delta \varepsilon_{a}^{2}+\varepsilon_{v_{i}} \\
+\frac{0.5 \Delta \varepsilon_{a}^{3} q_{i} n_{s}+271.9 h^{2} \Delta \varepsilon_{a}^{3} e}{n_{s} e \sigma_{3}}-\frac{2.1 E(-4) h^{3} \varepsilon_{v_{i}}}{n_{s} e^{2} \Delta \varepsilon_{a}^{2} \sigma_{3}} \\
+ \\
+\frac{0.2 \varepsilon_{v_{i}} q_{i} \Delta \varepsilon_{a}-0.3 \varepsilon_{a}^{2} \Delta \varepsilon_{a}-1.3 E(-8) C_{u} C_{c} \varepsilon_{a}^{4} q_{i}}{\varepsilon_{a} q_{i} \Delta \varepsilon_{a}}+0.05
\end{gathered}
$$

Figures 2 to 4 show deviator stress-axial strain and volumetric strain-axial strain curves predicted by the EPR models in Equations 6 and 7 against the experimental results for data sets that were used to train the models. A comparison was also made between the predictions of the ANN models suggested by Penumadu and Zhao (1999) and EPR results for the training data cases. Typical results are presented in Figure 5.

After training, the performance of the trained EPR models was verified using 39 sets of validation data which had not been introduced to EPR during the training phase. This was done to evaluate the generalisation capabilities of the developed models to unseen cases of data. Figures 6 to 8 show predictions made by the developed EPR models against the experimental data which were not previously seen by EPR and were only used to validate the models. The predicted data sets shown in these figures were obtained from the developed EPR models using all input parameters directly acquired from experimental test results which were kept unseen to EPR during the model development process implementing non-incremental approach. A comparison was also made, in these figures, with the predictions of the ANN models suggested by Penumadu and Zhao (1999).

Comparison of the results and the high COD values for the EPR models (Table 3) indicate the excellent performance of these models in capturing the underlying relationships between the contributing parameters and the deviator stress and volumetric strain response of granular soils and also in generalizing the training to predict the shearing behaviour of these types of soils under unseen conditions. The results also show that EPR over performs ANN and its results are a closer match to the actual experimental data. 


\section{Predicting entire stress paths using the EPR models}

The EPR models (Equations 6 and 7) were used to predict the entire stress paths, incrementally, point by point, in $q: \varepsilon_{a}$ and $\varepsilon_{v}: \varepsilon_{a}$ spaces. Results from four different sets of (testing) data were used to evaluate the ability of the incremental EPR models to predict the complete behaviour of granular soils during the entire stress paths. The values of average grain size, coefficients of uniformity and curvature, hardness, shape factor, void ratio and the confining pressure represented the initial conditions of the soil. Other contributing parameters including axial strain and the current values of deviator stress and volumetric strain were updated in each incremental step, considering the values from the previous increment and the EPR models outputs in response to an axial strain increment. Figure 9 illustrates the procedure followed for updating of the input parameters and building the entire stress path for the shearing stage of a triaxial test.

At the start of the shearing stage in a conventional triaxial experiment, the values of all parameters were known. Then, for a prescribed increment of axial strain $\left(\Delta \varepsilon_{a}\right)$ the values of $q_{i+1}, \varepsilon_{v, i+1}$ were calculated from the EPR models (Equations 6 and 7) respectively). For the next increment, the values of $\varepsilon_{a, i}, q_{i}$ and $\varepsilon_{v, i}$ were updated as:

$$
\begin{aligned}
& q_{i}=q_{i+1} \\
& \varepsilon_{v, i}=\varepsilon_{v, i+1} \\
& \varepsilon_{a, i}=\varepsilon_{a, i}+\Delta \varepsilon_{a}
\end{aligned}
$$

The incremental procedure was continued until all the points on the curves were predicted and the curves were established. Figures 10 to 13 show the comparisons between the four complete curves predicted using the EPR models following the above incremental procedure and the actual experimental results for 4 data sets. The predicted data sets shown in these figures were obtained from the developed EPR models by using the predictions at increment $(\mathrm{j})$ as input parameters to determine the soil response at increment $(j+1)$. The data for the tests used to 
demonstrate the capabilities of EPR models to reproduce the entire stress paths had not been introduced to the EPR during the model development process.

The results revealed that the predictions were in a very good agreement with the experimental results. Despite the fact that the entire curves had been predicted point by point and the errors of prediction of the individual points were accumulated in the process, the EPR models were robustly able to predict the complete stress paths. This shows that EPR framework is very effective in modelling the shearing behaviour of granular soils and is able to make reliable and highly accurate predictions.

\section{Sensitivity analysis}

A parametric study was carried out on random validation sets of data to evaluate the response of the models to changes in input parameters. This was done through a basic approach to sensitivity analysis by fixing all but one input variable to their mean values and varying the remaining one within the range of its maximum and minimum values available in data. Results of the sensitivity analysis are shown in Figures 14 to 16. As expected increasing the average particle size (which indicates that the soil grains are getting coarser) causes the shear strength of the soil to increase (Figure 14a).

Considering the fact that, in case of granular soils, the best way to compact a soil sample is by vibration rather than compression because of the friction between the coarse grains which increases under compression and makes it more difficult for the soil grains to move and fill up the voids, Figure $14 \mathrm{~b}$ correctly shows the negligible effect of increase in particle size on volumetric strain under compression in granular soils.

Increasing the shape factor parameter shows that angularity of the soil increases resulting in higher friction and subsequently higher shear strength; however, as the soil grains gets more angular the possibility of crushing of the angular grains under stress also increases. The available data suggest that the breakdown stress $\left(\sigma_{B}\right)$, beyond which the particle breakdown 
occurs, in some types of sand could be as low as $1 \mathrm{kN} / \mathrm{cm}^{2}$ (Vesic and Clough 1968). Deviator stress levels at failure in most test results used in this study were well above this level exceeding $70000 \mathrm{kPa}$ in cases, which can be considered as evidence of particle breakage occurring. Figure 15 shows that, due to the opposing effects of increase in friction and crushing of angular soil grains under compression, the overall effect of increasing the shape factor, on shear strength and volumetric strain of granular soils are also negligible.

Increasing void ratio causes the shear strength to drop and also the volumetric strain to increase under shearing. These effects are also correctly predicted by the proposed models (Figure 16).

\section{Discussion and conclusions}

Pattern recognition techniques like artificial neural networks have been introduced as an alternative method of modelling the behaviour of complex systems in recent decades. These methods have the advantage that they do not require any simplifying assumptions in developing the models representing the behaviour of systems and can capture the behaviour materials straight from field measurements and/or experimental results; however, due to their black box nature, these methods are unable to provide the users with an easy to understand explicit model providing visible deep insight into the physics of the systems. In this research work the evolutionary polynomial regression (EPR) was introduced as an alternative technique with the capability of overcoming some of the issues related to other previously used artificial intelligence-based modelling techniques aiming at modelling the complex shearing behaviour of cohesionless soils.

In the EPR approach, no pre-processing of the data is required and there is no need for normalization or scaling of the data. An interesting feature of EPR is in the possibility of getting more than one model for complex phenomena. The best model is chosen on the basis of its performances on a testing set which is kept unseen to EPR during the model development stage. 
As a result of this study, two models were developed based on EPR to describe the deviator stress - axial strain and volumetric strain - axial strain behaviour of granular soils. It was shown that EPR has been able to capture the underlying relationships between various involved parameters directly from experimental triaxial data and developed models with the ability of predicting the shearing behaviour of granular soils to high accuracy levels. The EPR models were tested using data that were not used in the training phase of the EPR model development process; in this way, an unbiased performance indicator was obtained on the real prediction capability of the models. The results revealed that the EPR-based models were capable of generalizing the training to predict the behaviour of granular soils under conditions that have not been previously seen by EPR in the training stage. Through the comparison of the results it was also shown that the proposed EPR models outperformed ANN and provided closer predictions to the experimental data cases. An incremental approach was also taken and was successfully implemented to develop the entire stress paths for the shearing behaviour of granular soils using developed models with very good accuracy despite error accumulation. . A parametric study was also conducted to evaluate the effect of the contributing parameters on the predictions of the proposed EPR models. The results revealed the consistency of the suggested model predictions, considering the roles of various contributing parameters, with physical and engineering understandings of the shearing behaviour of granular soils. However, another interesting feature of EPR is that as more data becomes available, EPR can be retrained with the latest most comprehensive set of data to create more accurate and efficient models. The fact that EPR is capable of learning the material behaviour directly from raw experimental data makes the EPR-based Constitutive Modelling (EPRCM) the shortest route from the experimental research to the numerical modelling. A trained EPRCM can be incorporated into a finite element code just like a conventional constitutive model. This implementation can be done by using either incremental or total stress-strain strategies. An 
EPR-based finite element method can be used for solving boundary value problems in the same way as a conventional finite element method. Examples of implementation of EPR models in finite element analysis are already completed and published by the authors ( (Javadi, Mehravar, et al. 2009), (Javadi, Faramarzi and Ahangar-Asr 2012)).

\section{References}

Ahangar Asr, Alireza, and Akbar Javadi. 2016. "Air losses in compressed air tunnelling: a prediction model." Proceedings of the Institution of Civil Engineers - Engineering and Computational Mechanics.

Ellis, G W, C Yao, R Zhao, and D Penumadu. 1995. "Stress-strain modeling of sands using artificial neural networks." Journal of Geotechnical Engineering, ASCE 121 (5): 42935.

Erzin, Y. 2004. "Strength of Different Anatolian Sands in Wedge Shear,Triaxial Shear, and Shear Box Tests." The Middle East Technical University, PhD thesis.

Ghaboussi, J., D.A. Pecknold, M. Zhang, and R.M. Haj-Ali. 1998. "Autoprogressive training of neural network constitutive models." International Journal for Numerical Methods in engineering 42 (1): 105-126.

Giustolisi, O, and D Savic. 2006. "A symbolic data-driven technique based on evolutionary polynomial regression." Journal of Hydroinformatics 8 (3): 207-222.

Hardin, B O. 1985. "Crushing of soil particles.” Journal of Geotechnical Engineering, ASCE 111 (10): 1177-92.

Hussain M. S., Javadi A. A., Ahangar-Asr A, Farmani R. 2015. "A surrogate model for simulation-optimization of aquifer systems.” Journal of Hydrology 542-554.

Javadi, A A, and M Rezania. 2009. "Applications of artificial intelligence and data mining techniques in soil modelling." Geomechanics and Engineering, An International Journal 1 (1): 53-74.

Javadi, Akbar A, Asaad Faramarzi, and Alireza Ahangar-Asr. 2012. "Analysis of behaviour of soils under cyclic loading using EPR-based finite element method." Finite Elements in Analysis and Design 53-65.

Javadi, Akbar A, Moura Mehravar, Asaad Faramarzi, and Alireza Ahangar-Asr. 2009. “An Artificial Intelligence Based Finite Element Method." Transactions on Computers and Intelligent Systems 1-7. 
Lee, K L, and H B Seed. 1967. "Drained strength characteristics of sands." J. Soil Mech. and Found. Div., ASCE 93 (6): 117-141.

Lee, K L, H B Seed, and P Dunlop. 1967. "Effect of moisture on the strength of clean sand." J. Soil Mech. and Found. Div., ASCE 93 (6): 17-40.

Leslie, D D. 1975. "Shear strength of rock fill.” Physical Properties Engrg. Study No. 526, U.S. Army Corps of Engrs., Sausalito, CA.

Lo, K Y, and M Roy. 1973. "Response of particulate materials at high-pressures." Soils and Foundations,JSSMFE 13 (1): 61-76.

Marachi, N D, C K Chan, H B Seed, and J M Duncan. 1969. "Strength and deformation characteristics of rockfill materials." Report No. TE-69-5, Dept. of Civil Engrg., Univ. Of California, Berkeley, CA.

Miura, N, and S O-Hara. 1979. "Particle crushing of a decomposed granite soil under shear." Soils and Foundations, JSSMFE 19 (3): 1-14.

Miura, N, and T Yamanouchi. 1975. "Effect of water on the behavior of quartz-rich sand under high stresses." Soils and Foundations, JSSMFE 15 (4): 23-34.

Penumadu, D, and R Zhao. 1999. "Triaxial compression behavior of sand and gravel using arti®cial neural networks (ANN).” Computers and Geotechnics 24: 207-230.

Ponce, V M, and J M Bell. 1971. "Shear strength of sand at extremely low pressures." J. Soil Mech. and Found.Div., ASCE 97 (4): 625-639.

Ramamurthy, T, V K Kanitar, and K Prakash. 1974. "Behavior of coarse-grained soils under high stresses." Indian Geotech. J. 4 (1): 39-63.

Raymond, G P, and J R Davies. 1978. "Triaxial tests on dolomite railroad ballast.” J. Geotech. Engrg., ASCE 104 (6): 737-751.

Raymond, G P, and V A Diyaljee. 1979. "Railroad ballast load ranking classification.” J. Geotech. Engrg., ASCE 105 (10): 1133-1153.

Rowe, C W, and L Barden. 1964. "Importance of free ends in triaxial testing." Journal of the Soil Mechanics and Foundations Division, ASCE 90 (1): 1-28.

Vesic, Aleksandar S, and G Wayne Clough. 1968. "Behaviour of Granular Materials Under High Stresses." Soil Mechanics and Foundations Division 661-688.

Wu, T H. 1957. "Relative density and shear strength of sands." J. Soil Mech. and Found. Div., ASCE 83 (1): 1161:1-23. 


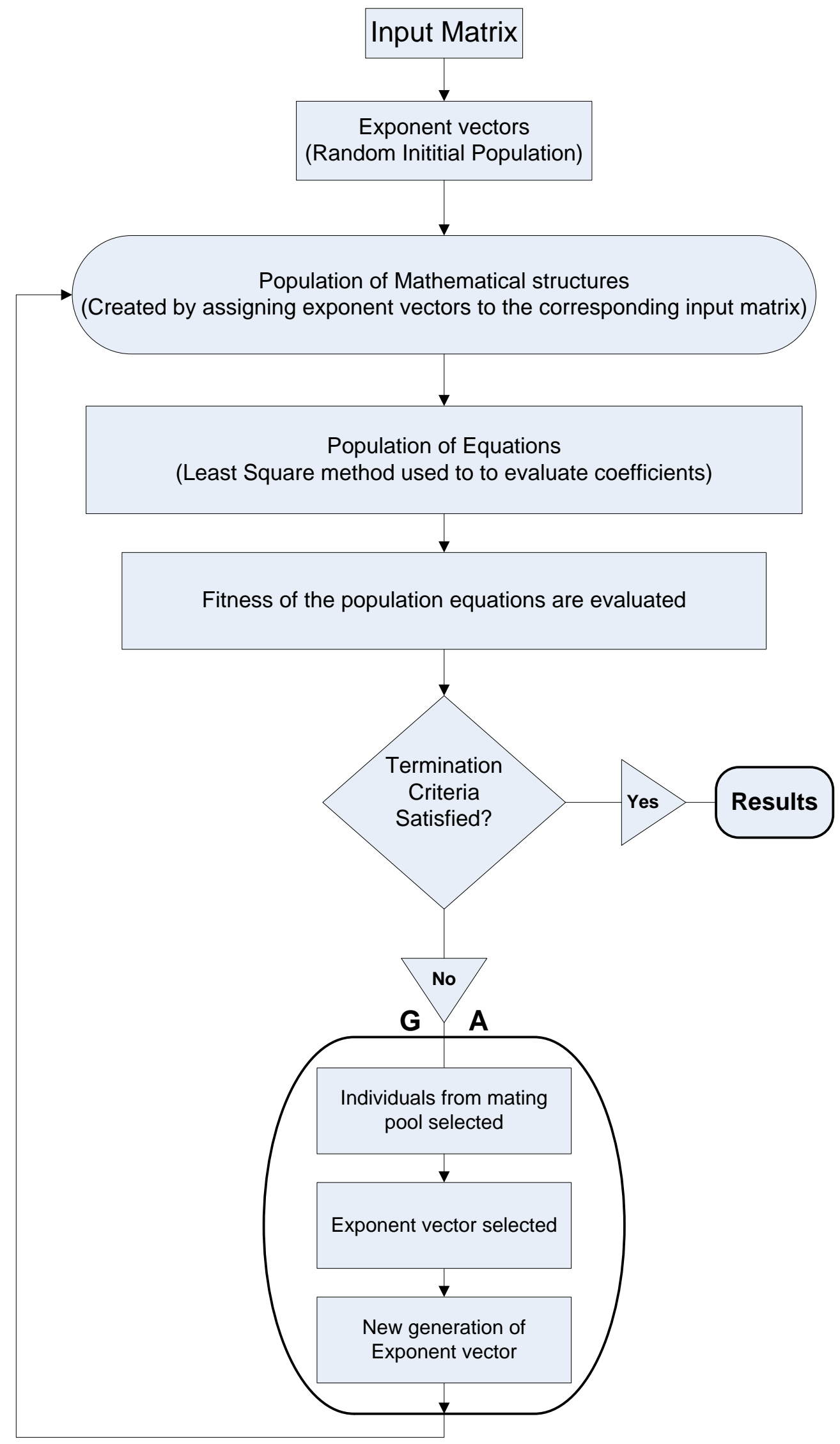

Figure 1: Flow diagram for EPR procedure 


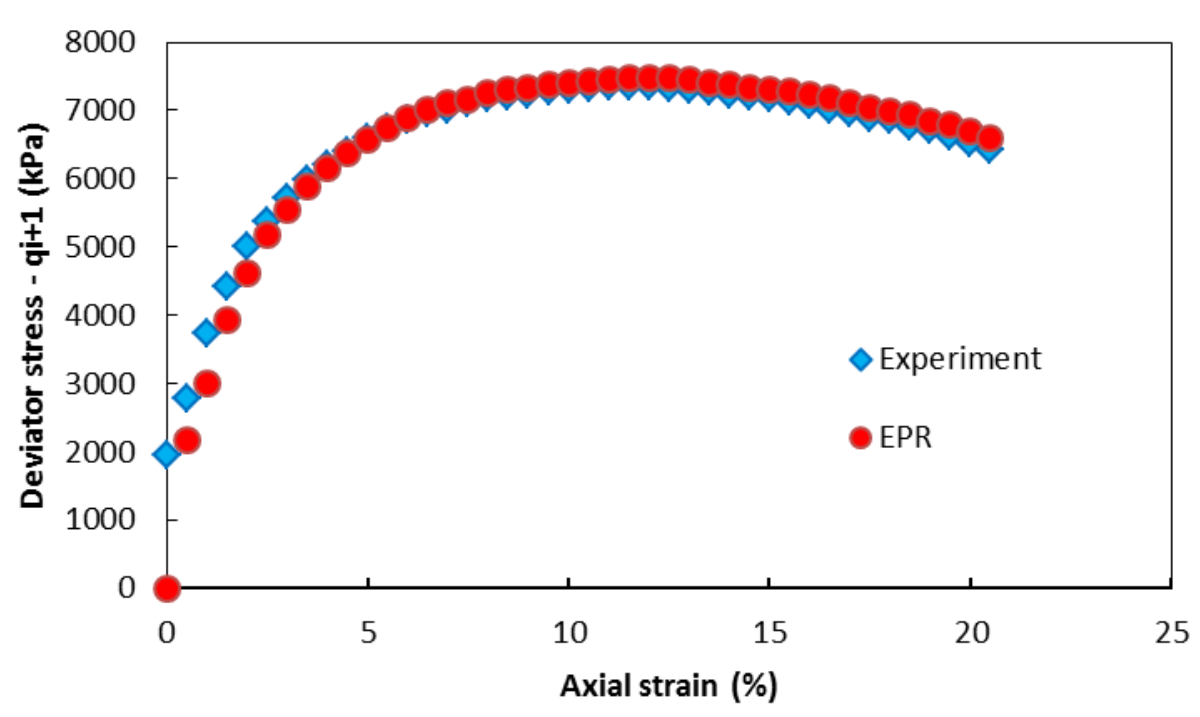

(a)

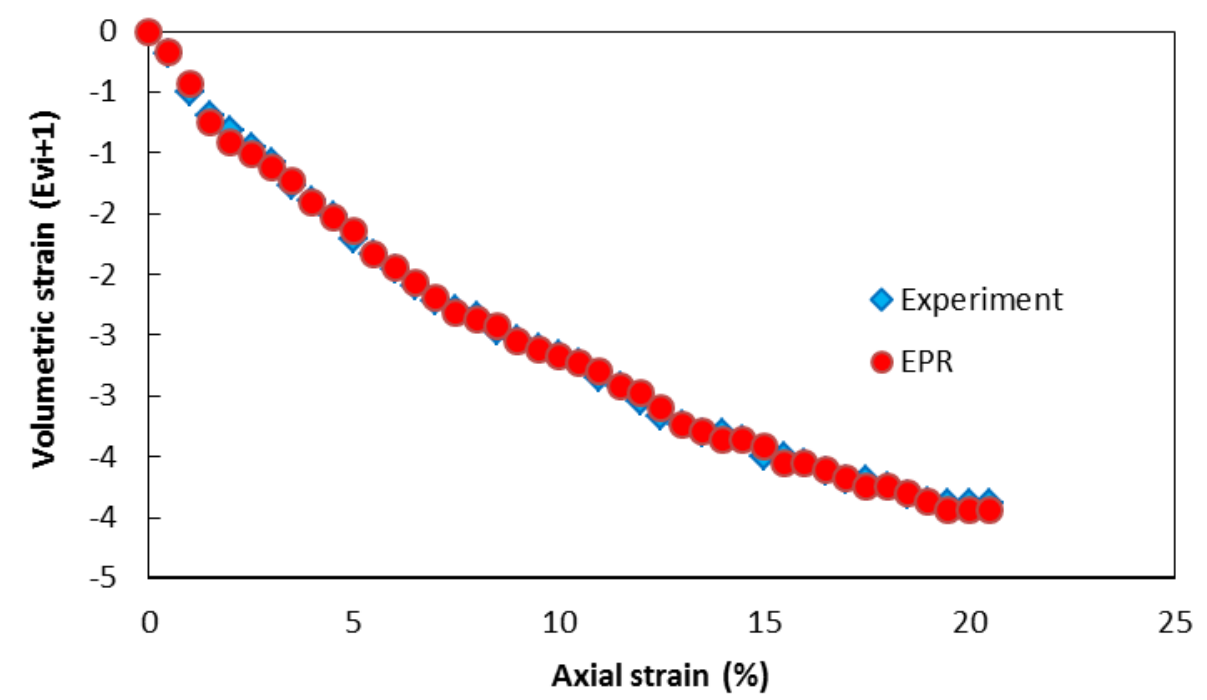

(b)

Figure 2: (a) Deviator stress-axial strain and (b) volumetric strain-axial strain curves predicted by the EPR models compared to experimental data $\left(\sigma_{3}=2932 \mathrm{kPa}\right)$ - training data case (Experimental data from Lee and Seed (1967)) 


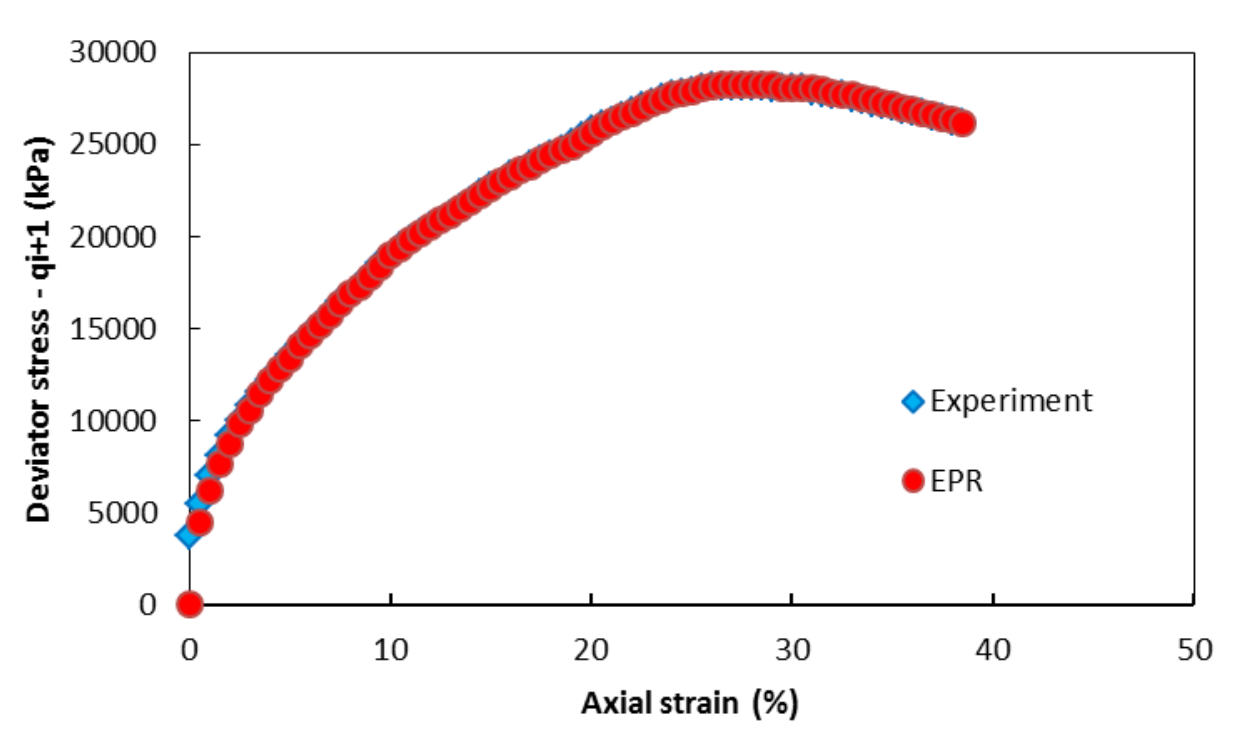

(a)

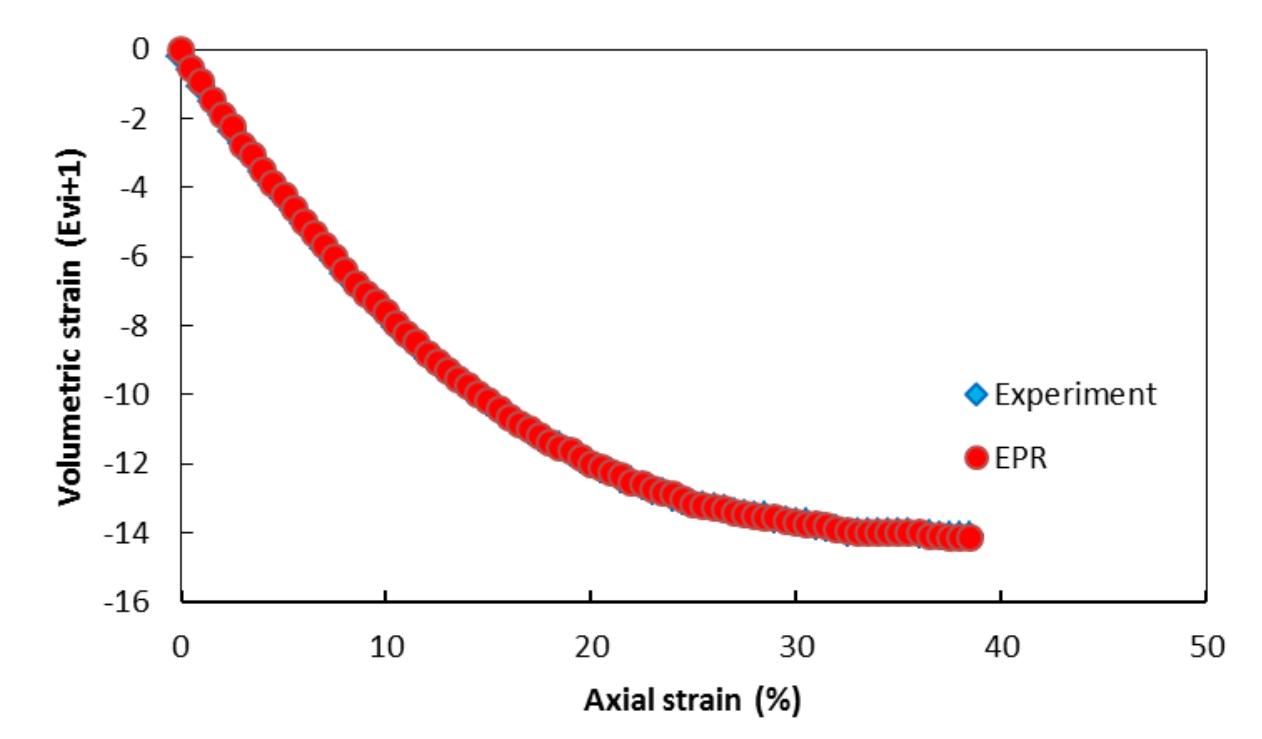

(b)

Figure 3: (a) Deviator stress-axial strain and (b) volumetric strain-axial strain curves predicted by the EPR models compared to experimental data $\left(\sigma_{3}=11767 \mathrm{kPa}\right)$ - training data case (Experimental data from Lee and Seed (1967)) 


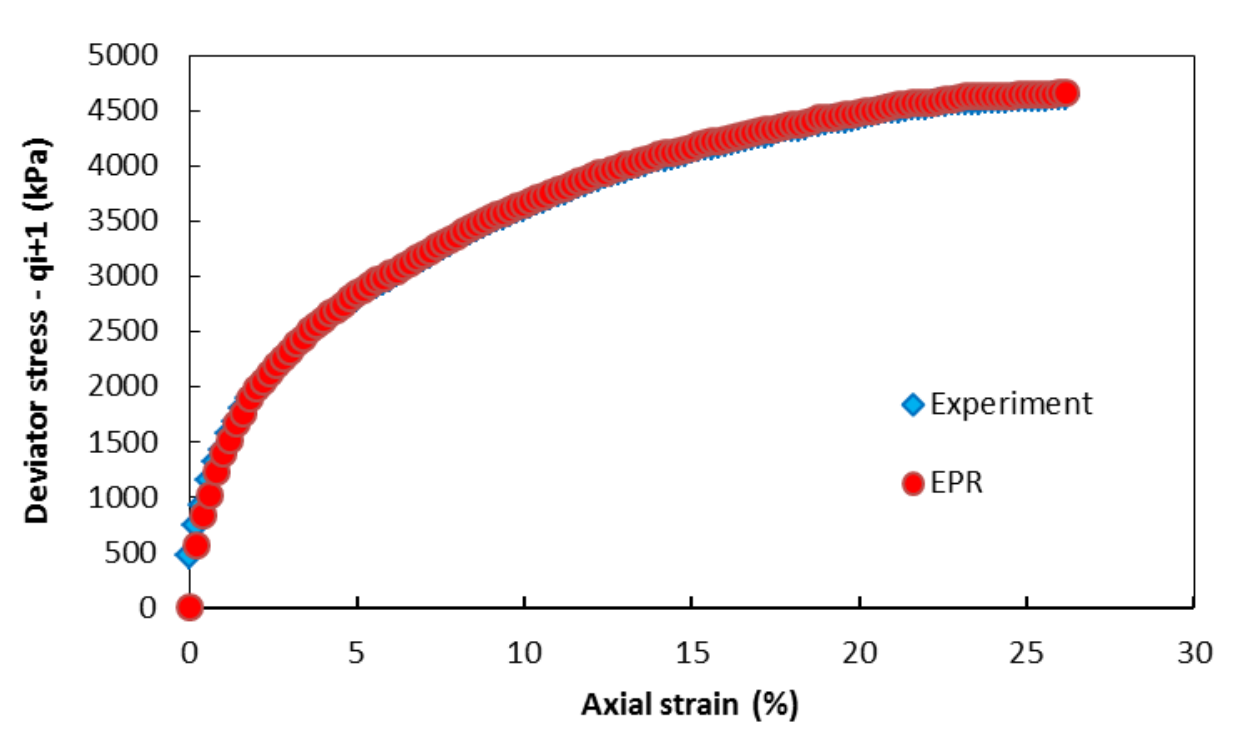

(a)

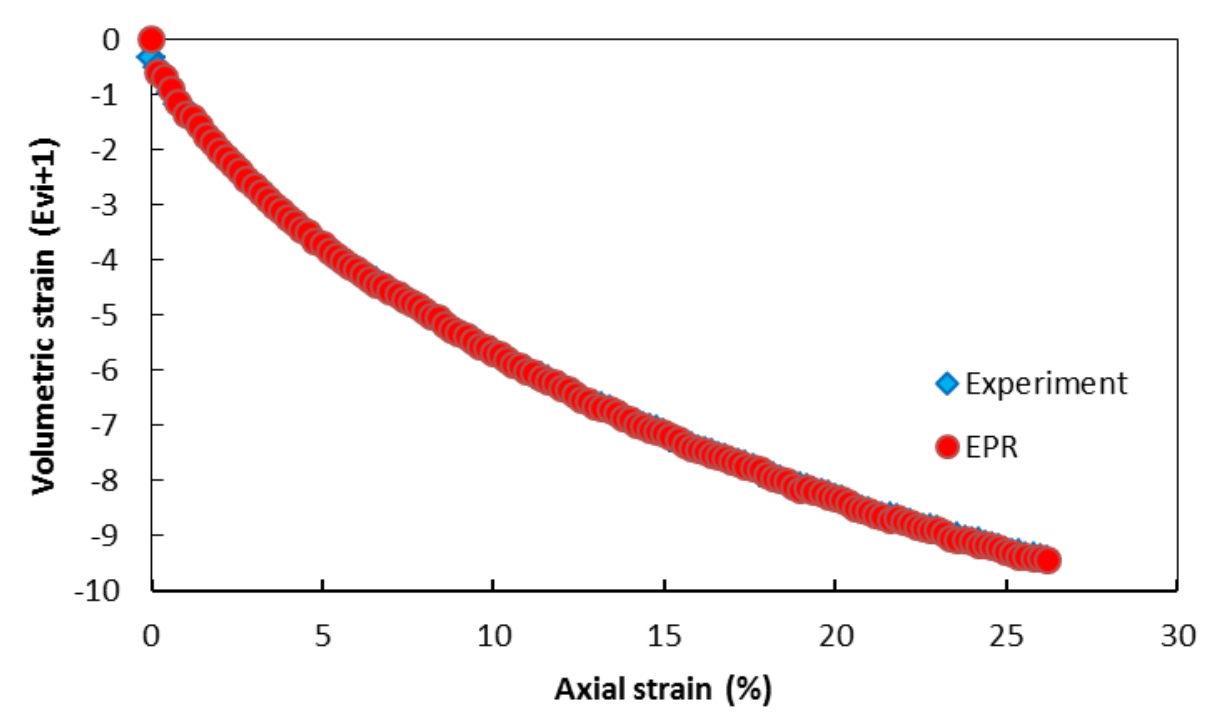

(b)

Figure 4: (a) Deviator stress-axial strain and (b) volumetric strain-axial strain curves predicted by the EPR models compared to experimental data $\left(\sigma_{3}=1961 \mathrm{kPa}\right)$ - training data case (Experimental data from Lee and Seed (1967)) 


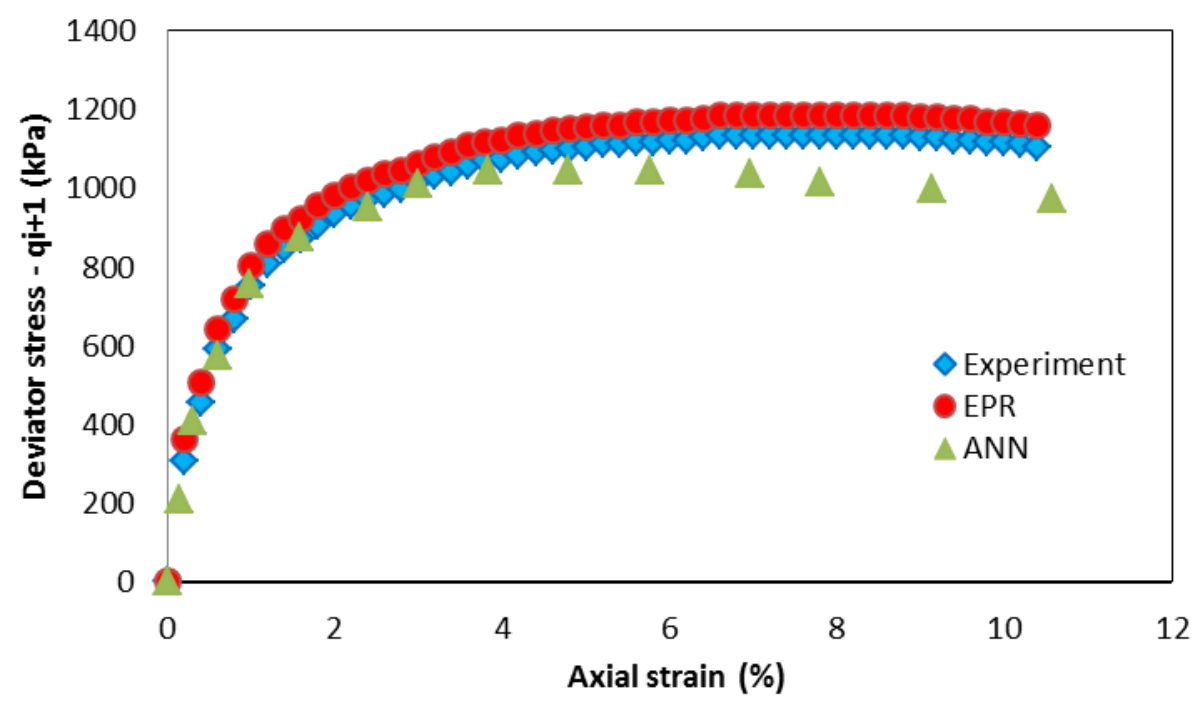

(a)

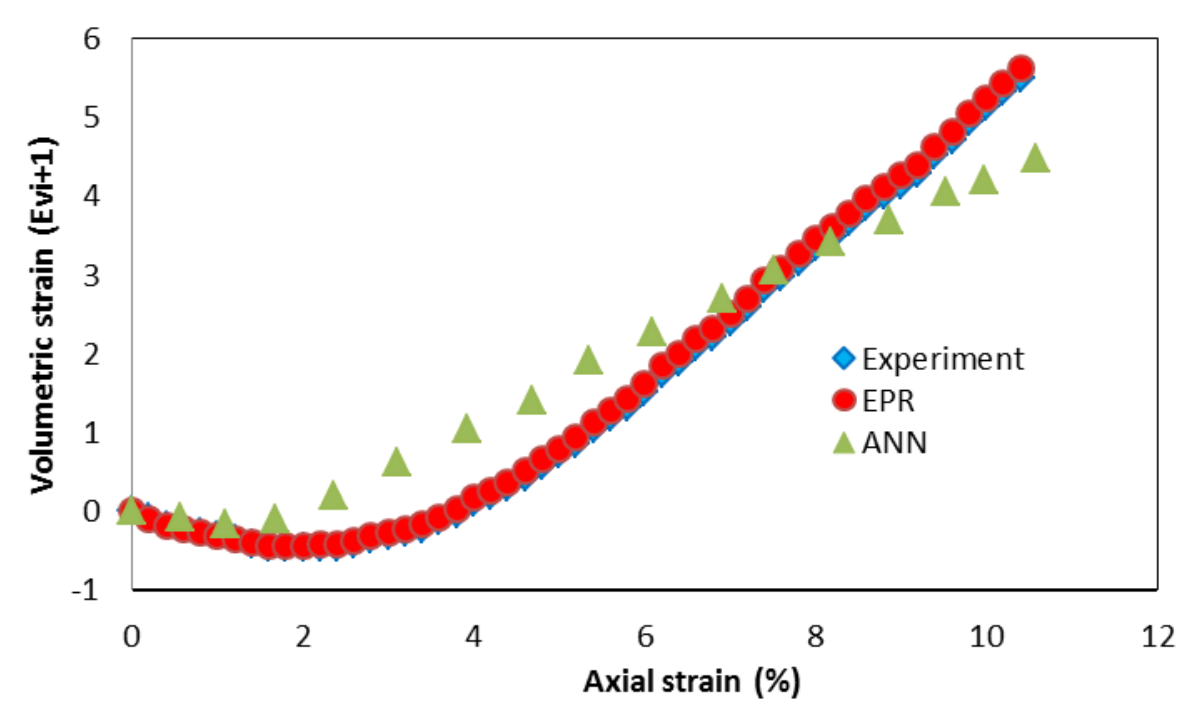

(b)

Figure 5: (a) Deviator stress-axial strain and (b) volumetric strain-axial strain curves predicted by the EPR models compared to experimental data and ANN model predictions $\left(\sigma_{3}=275 \mathrm{kPa}\right)-$ training data case (Experimental data from Wu (1957)) 


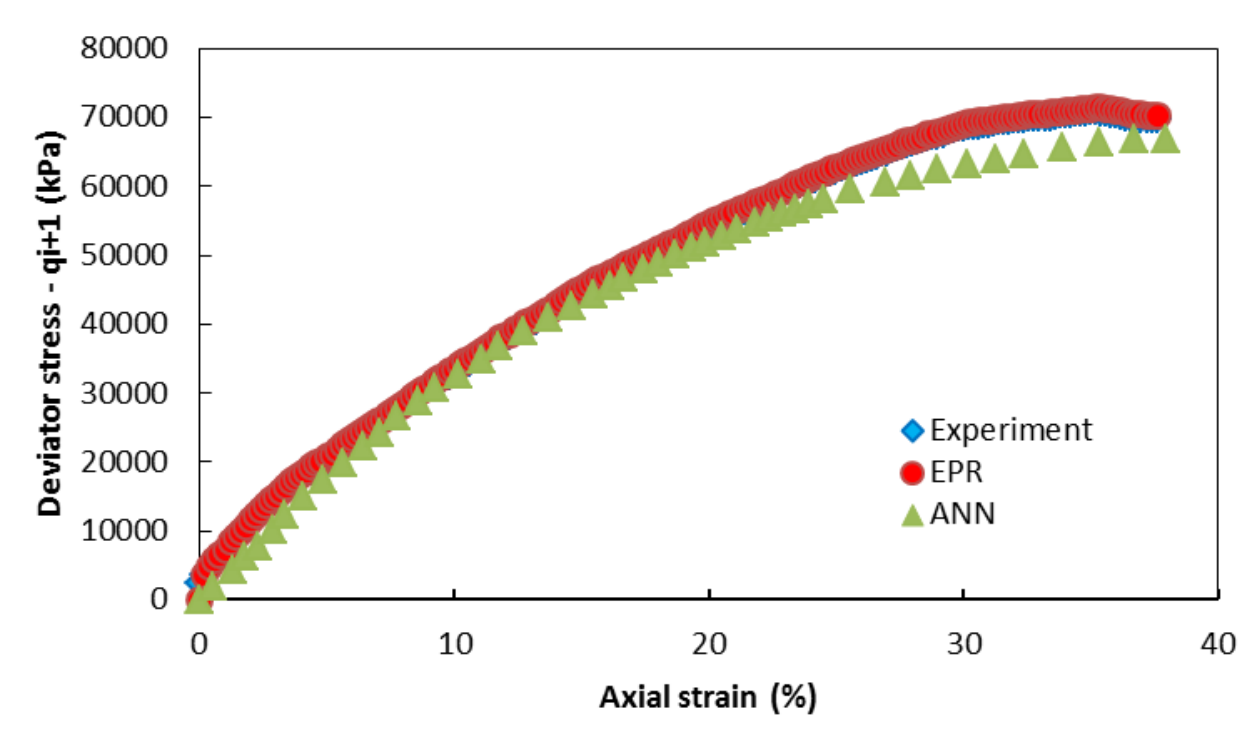

(a)

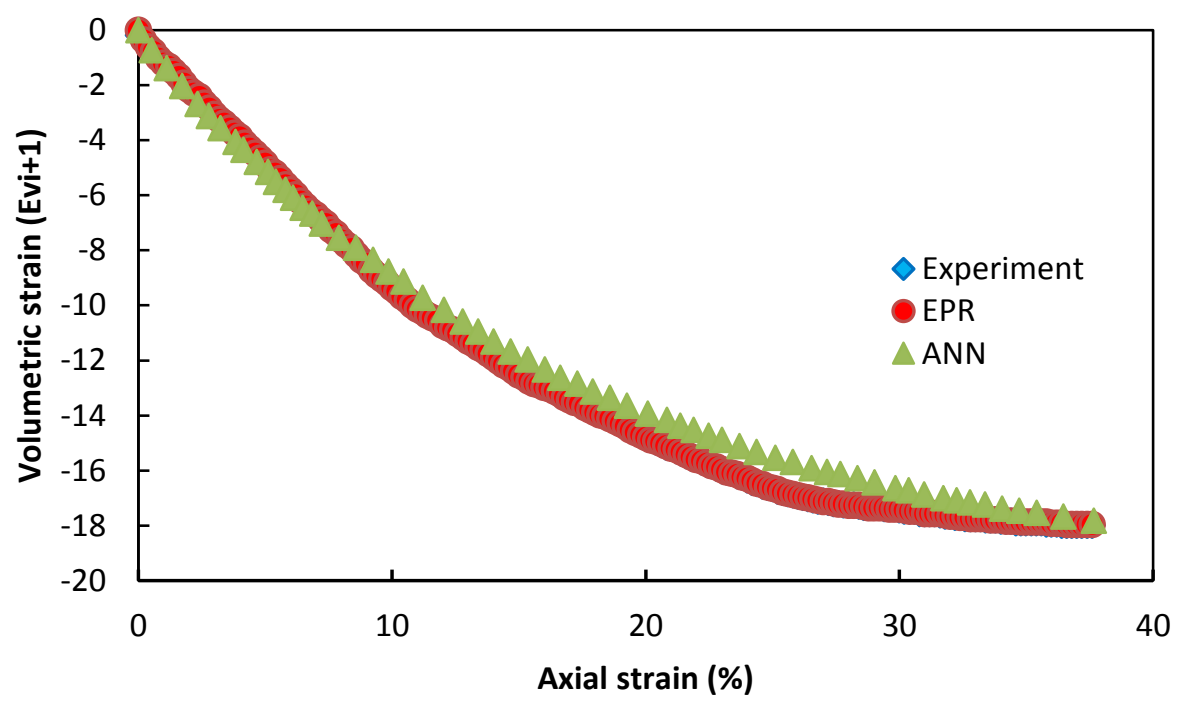

(b)

Figure 6: (a) Deviator stress-axial strain and (b) volumetric strain-axial strain curves predicted by the EPR models compared to experimental data and ANN model predictions $\left(\sigma_{3}=11767 \mathrm{kPa}\right)-$ testing data case (Experimental data from Lee and Seed (1967)) 


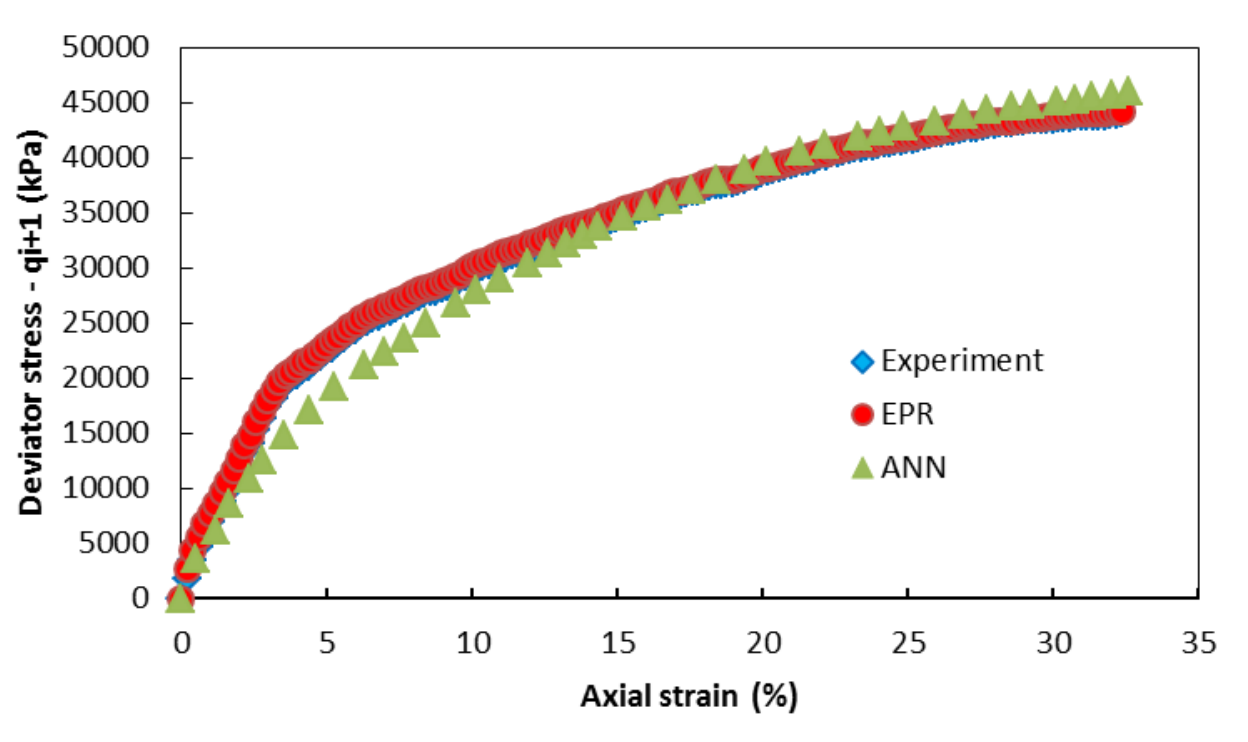

(a)

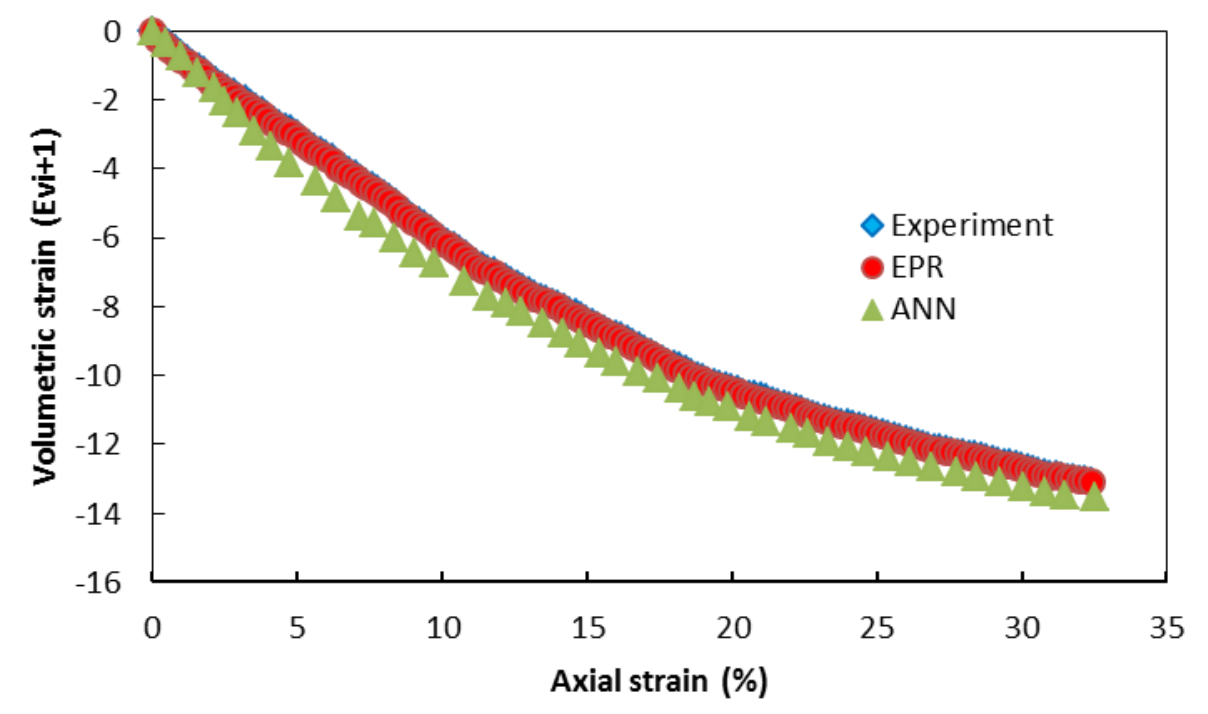

(b)

Figure 7: (a) Deviator stress-axial strain and (b) volumetric strain-axial strain curves predicted by the EPR models compared to experimental data and ANN model predictions $\left(\sigma_{3}=19613 \mathrm{kPa}\right)$ - testing data case (Experimental data from Miura and Yamanouchi (1975)) 


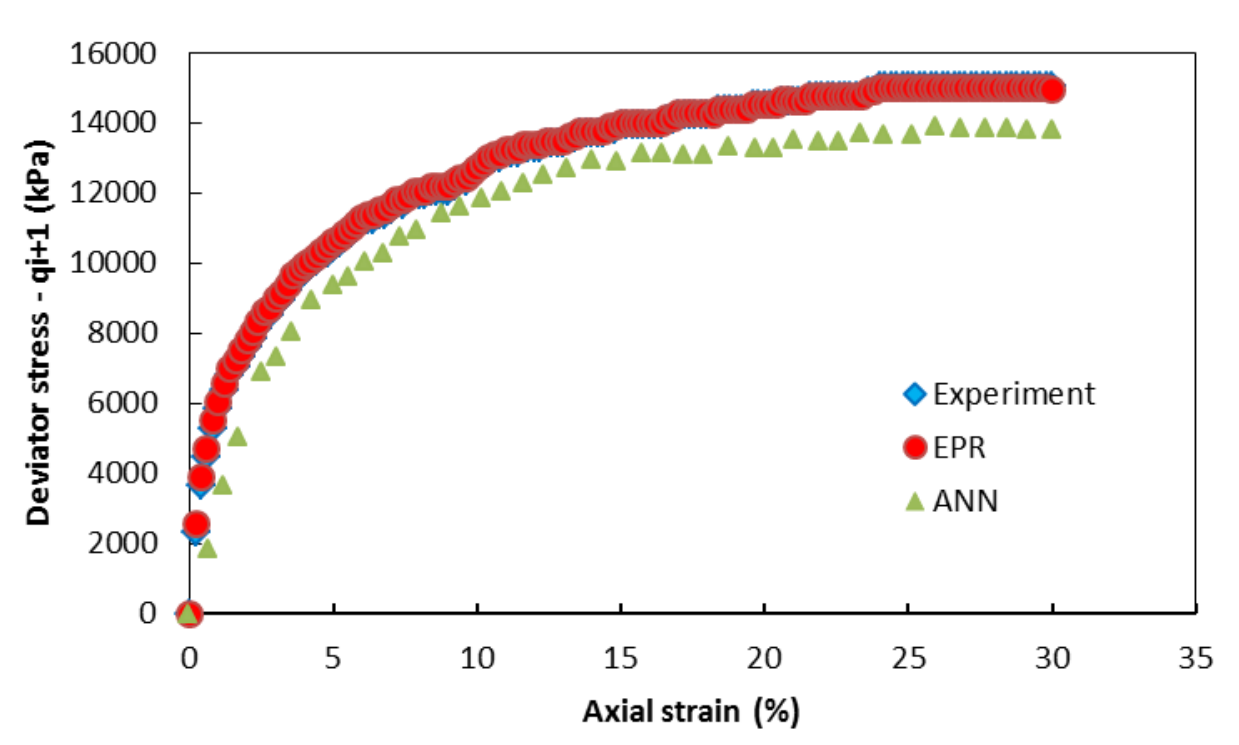

(a)

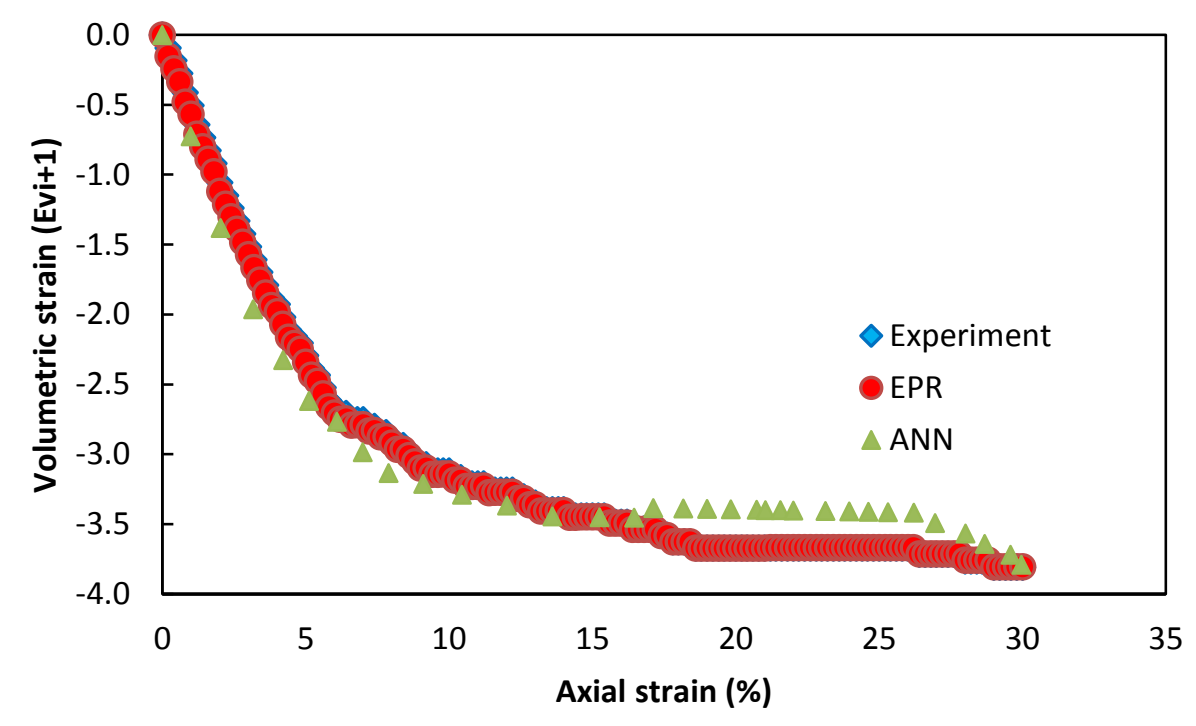

(b)

Figure 8: (a) Deviator stress-axial strain and (b) volumetric strain-axial strain curves predicted by the EPR models compared to experimental data and ANN model predictions $\left(\sigma_{3}=5515 \mathrm{kPa}\right)$ - testing data case (Experimental data from Lo and Roy (1973)) 


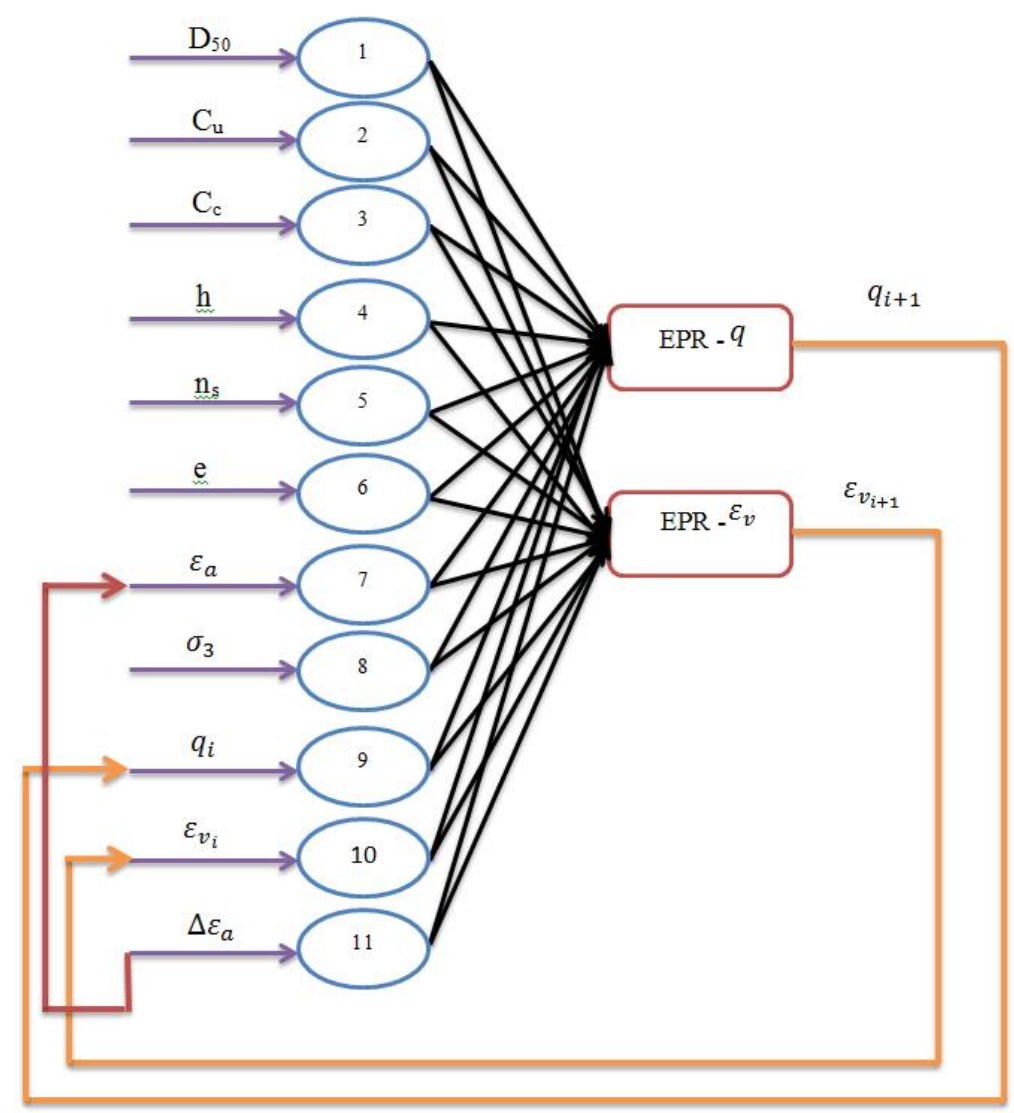

Figure 9: Incremental procedure for predicting the entire stress path 


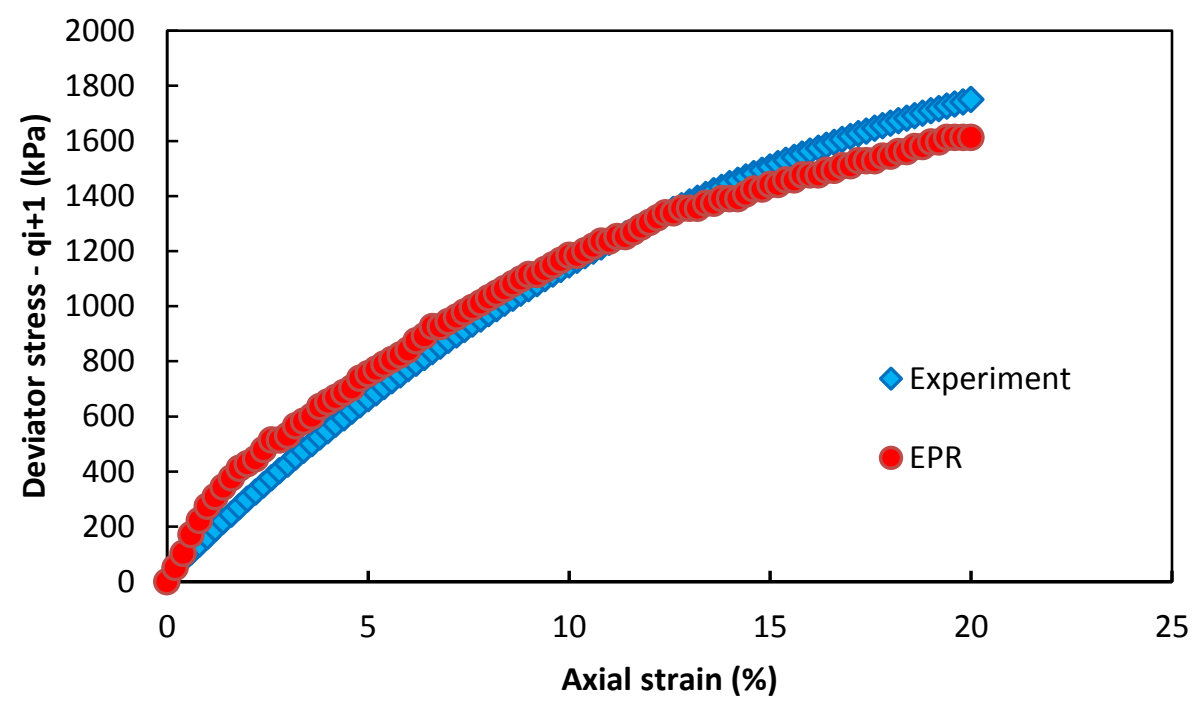

(a)

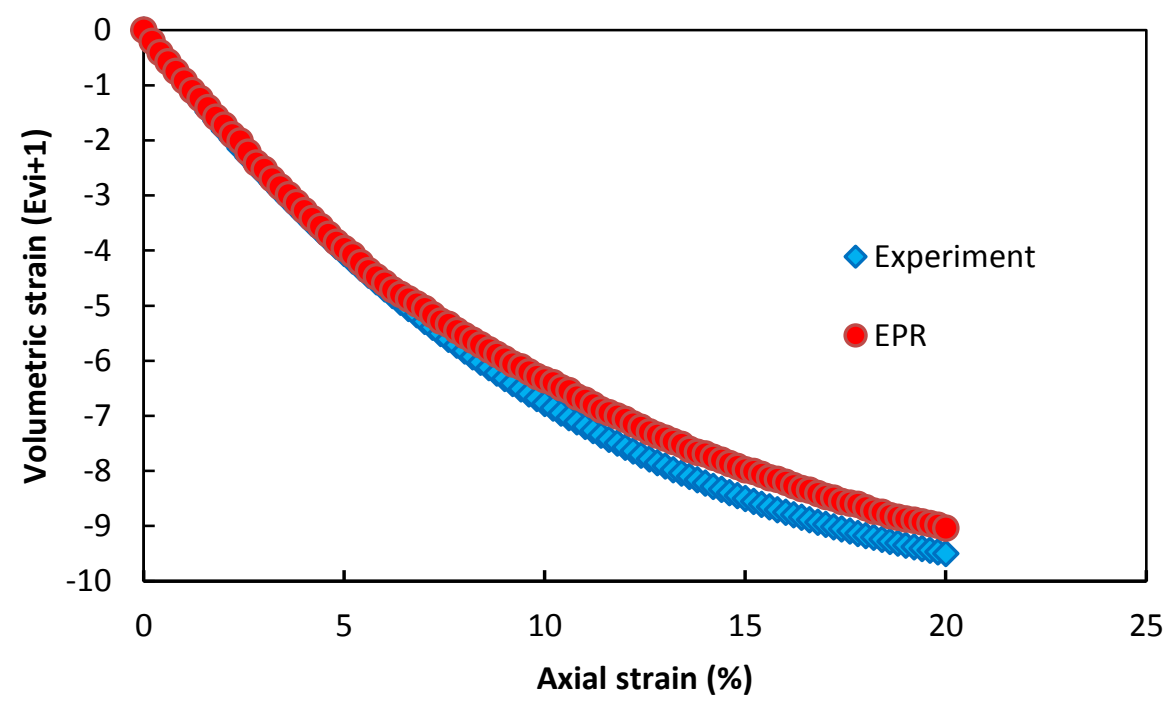

(b)

Figure 10: (a) Deviator stress-axial strain and (b) volumetric strain-axial strain curves predicted by the EPR models compared to experimental data $\left(\sigma_{3}=413 \mathrm{kPa}\right)$ - testing data case, entire stress path prediction (Experimental data from Leslie (1975)) 


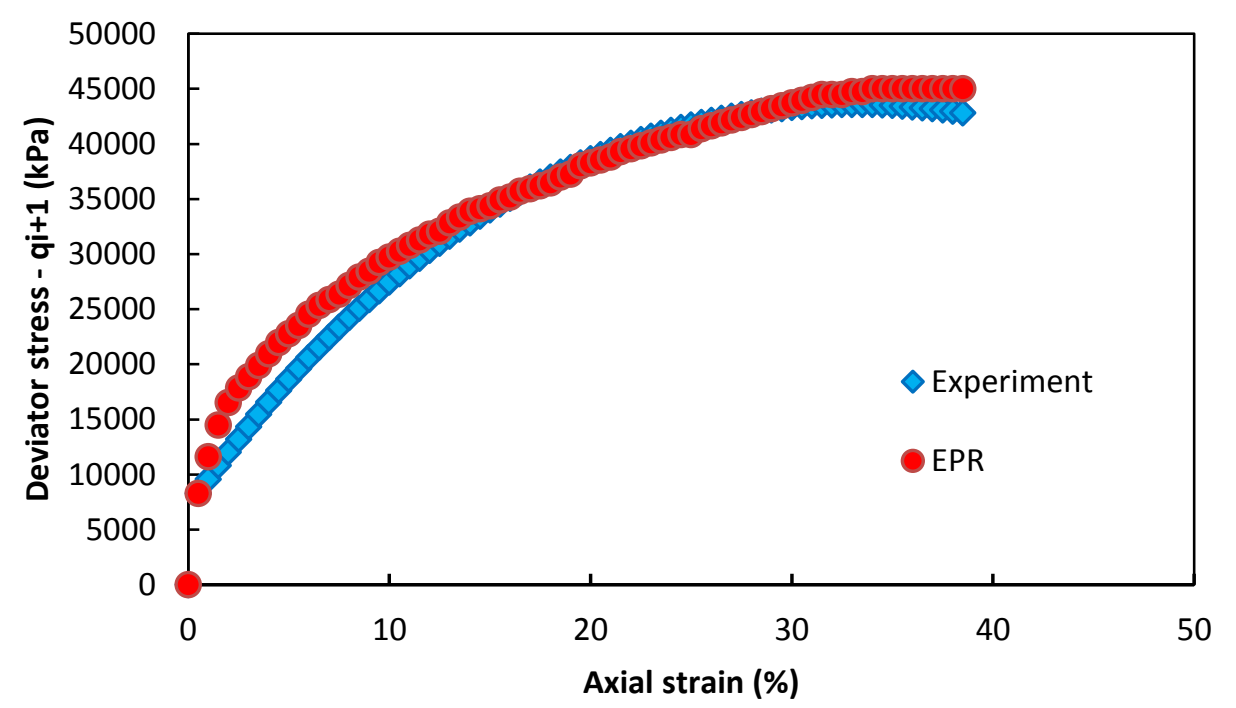

(a)

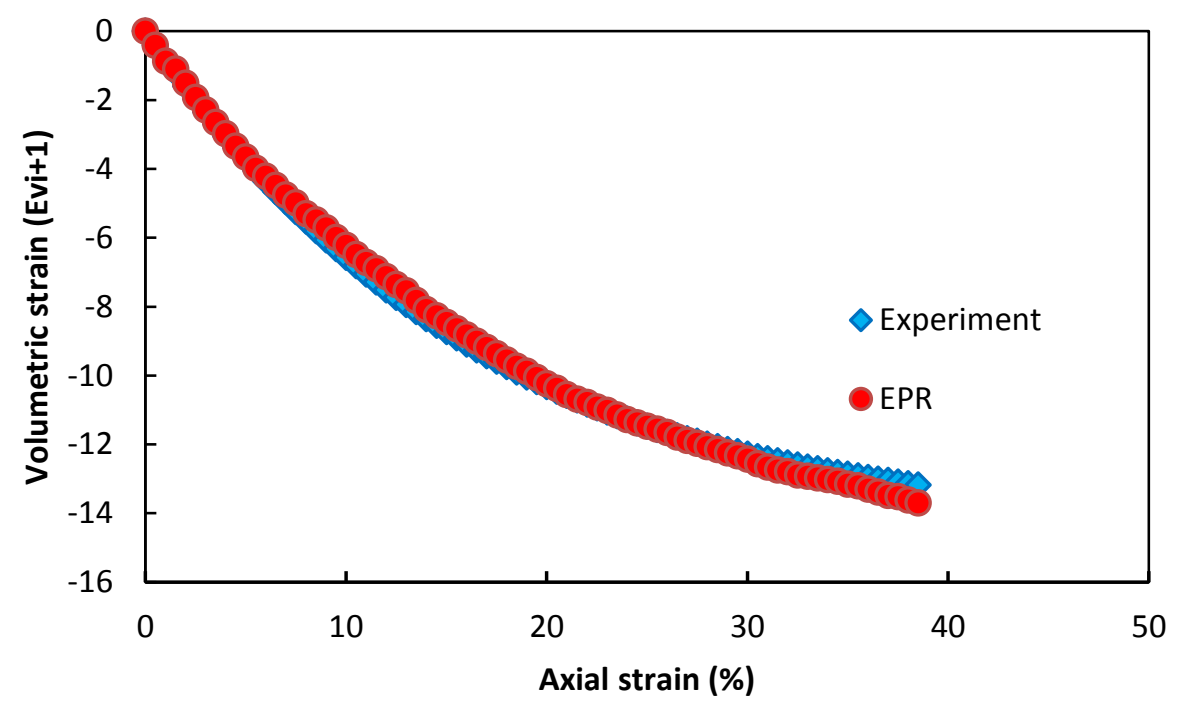

(b)

Figure 11: (a) Deviator stress-axial strain and (b) volumetric strain-axial strain curves predicted by the EPR models compared to experimental data $\left(\sigma_{3}=19613 \mathrm{kPa}\right)$ - testing data case, entire stress path prediction (Experimental data from Miura and Yamanouchi (1975)) 


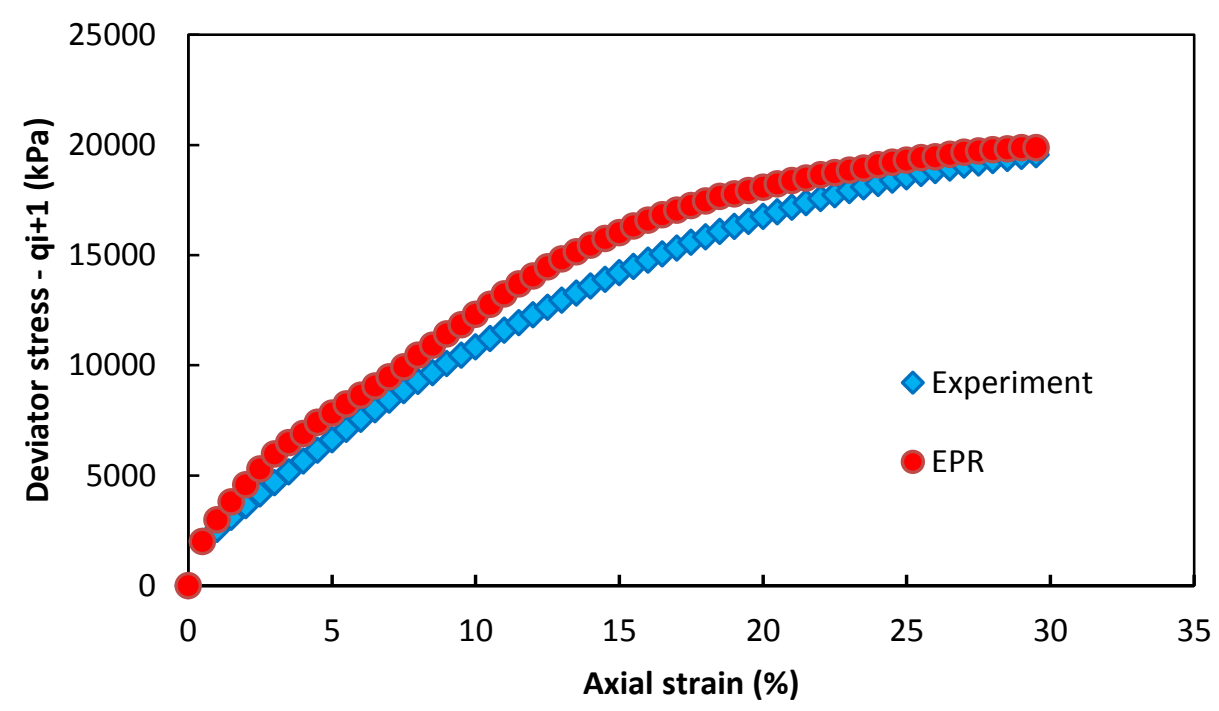

(a)

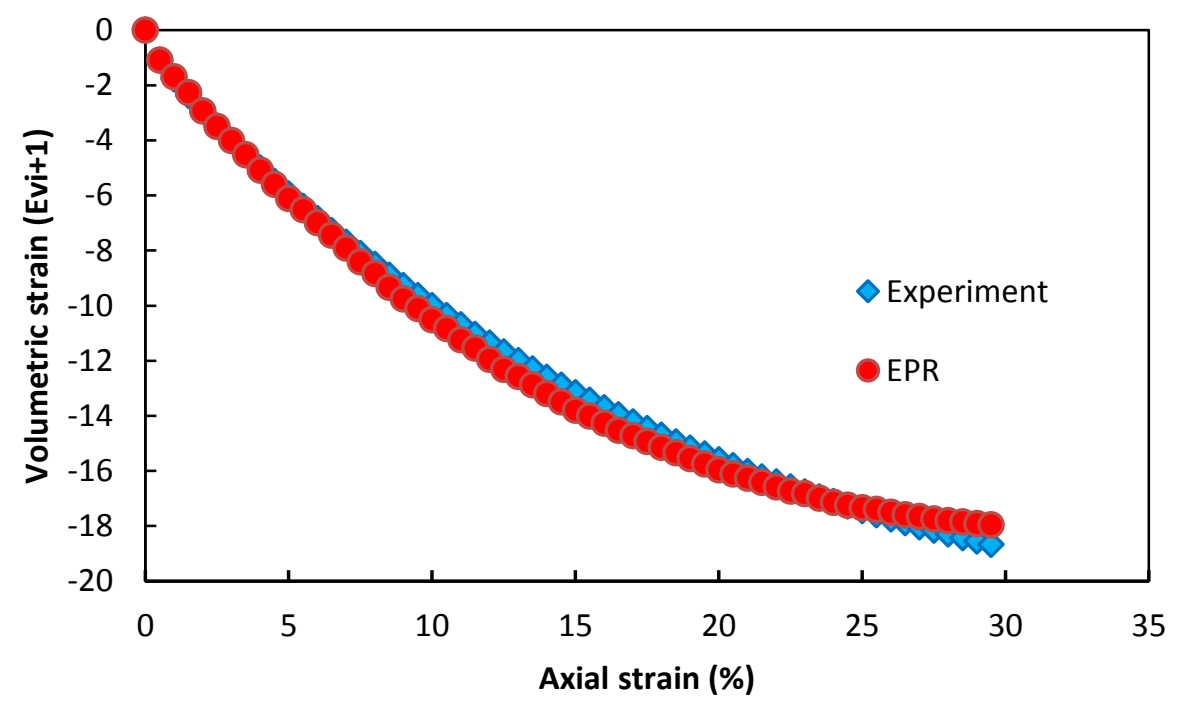

(b)

Figure 12: (a) Deviator stress-axial strain and (b) volumetric strain-axial strain curves predicted by the EPR models compared to experimental data $\left(\sigma_{3}=8276 \mathrm{kPa}\right)$ - testing data case, entire stress path prediction (Experimental data from Ramamurthy, Kanitar and Prakash (1974)) 


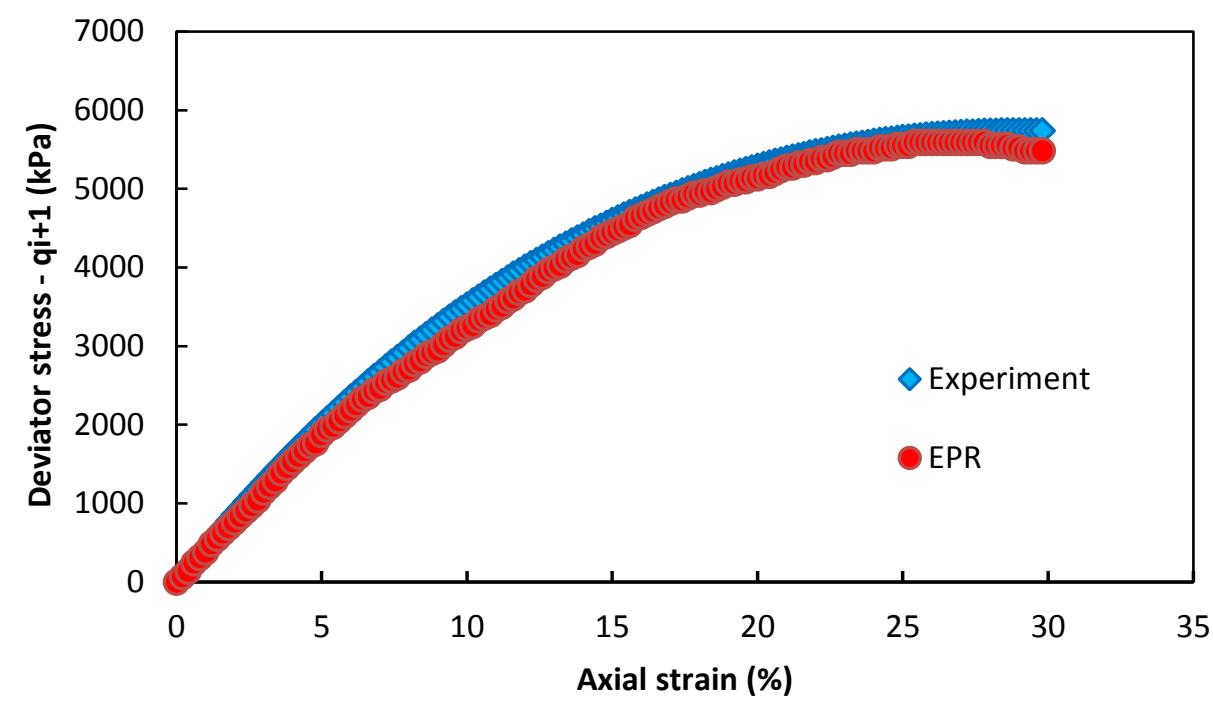

(a)

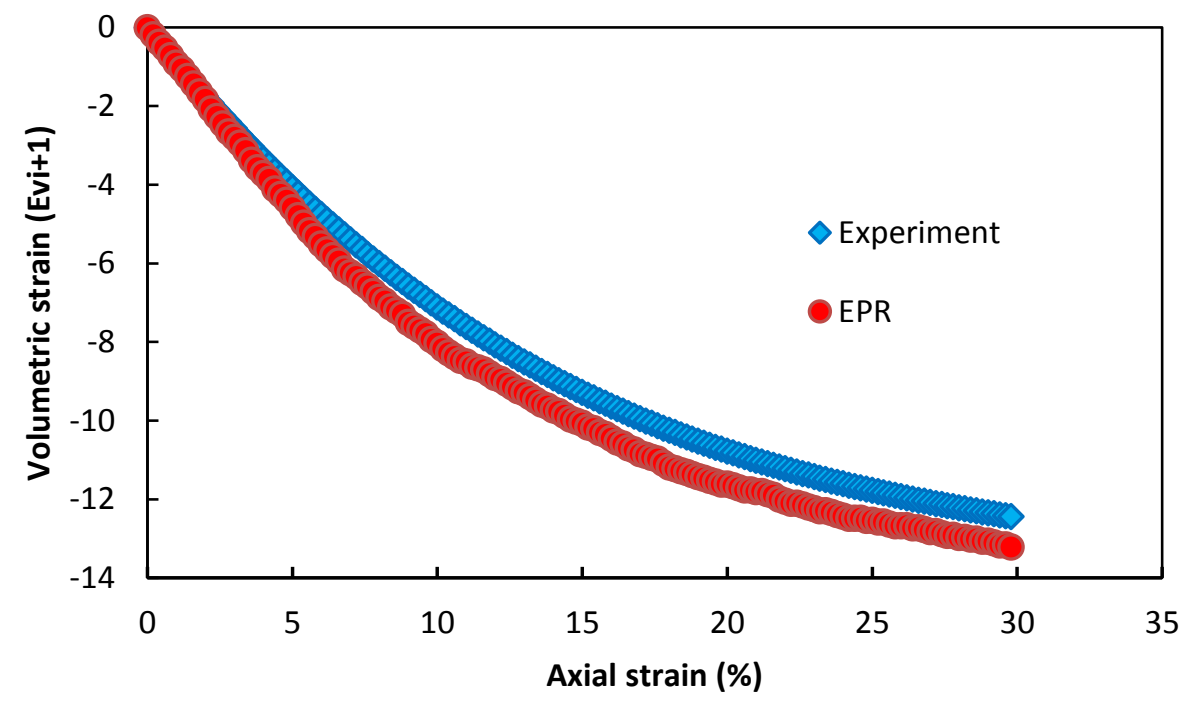

(b)

Figure 13: (a) Deviator stress-axial strain and (b) volumetric strain-axial strain curves predicted by the EPR models compared to experimental data $\left(\sigma_{3}=2068 \mathrm{kPa}\right)$ - testing data case, entire stress path prediction (Experimental data from Leslie (1975)) 


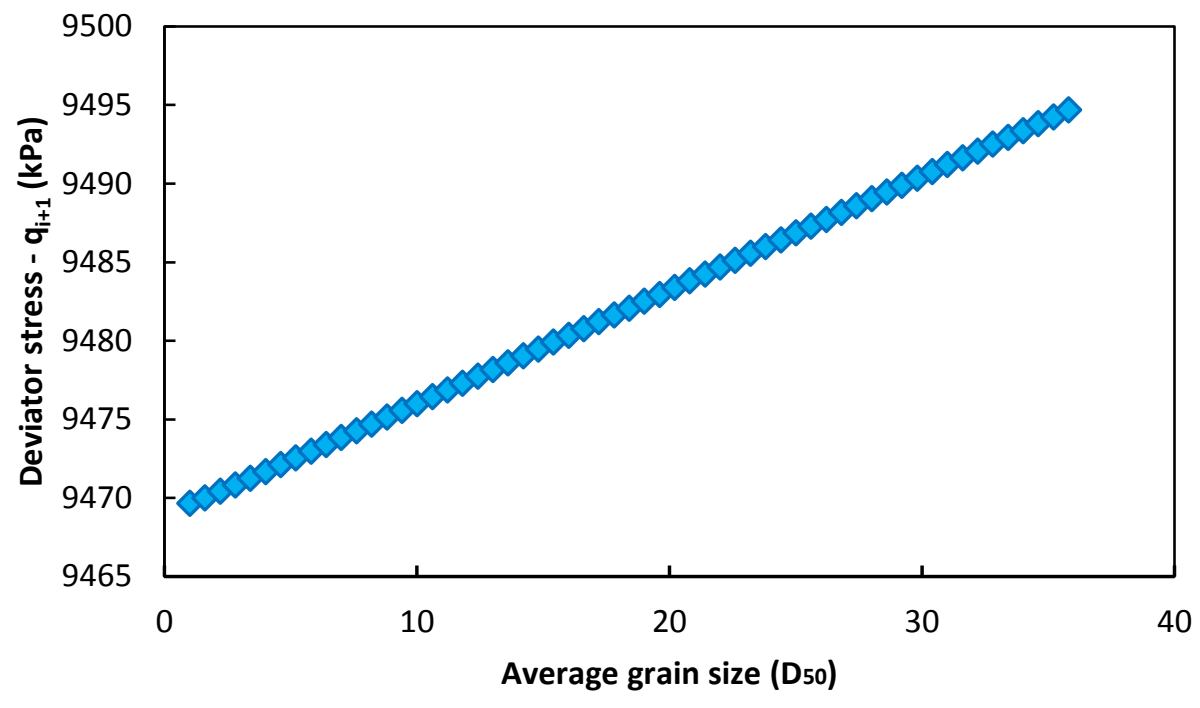

(a)

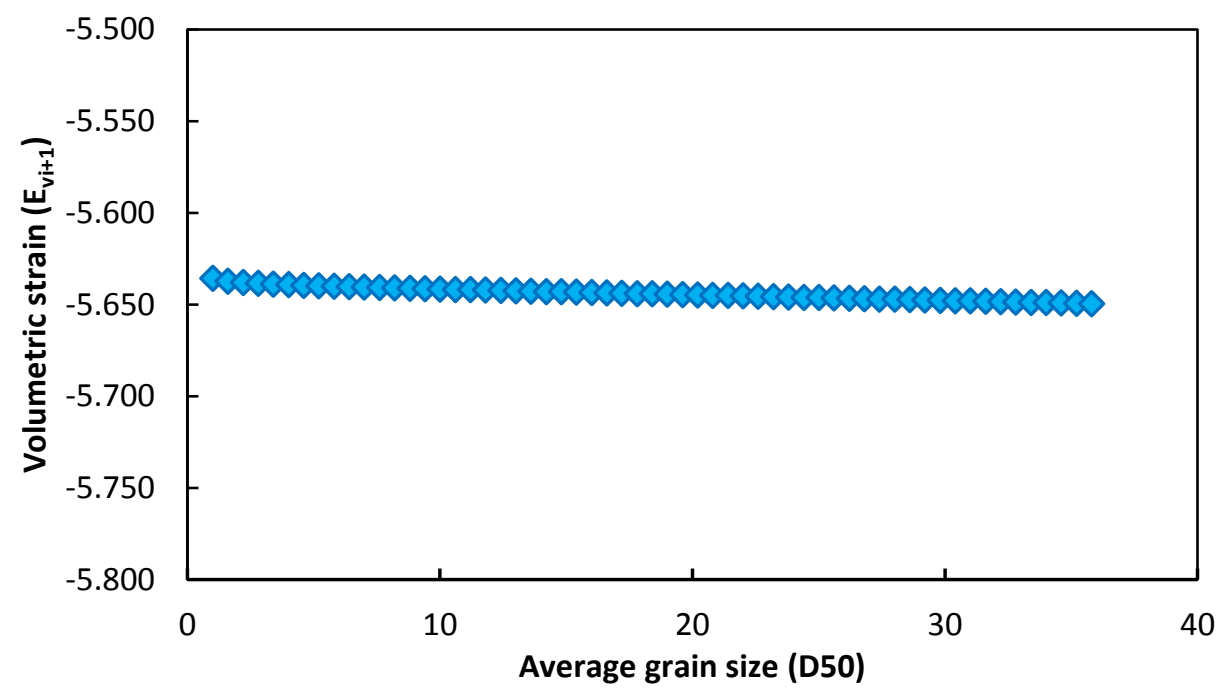

(b)

Figure 14: Sensitivity analysis results considering the effect of average grain size $D_{50}$ on EPR model predictions for (a) deviator stress and (b) volumetric strain. 


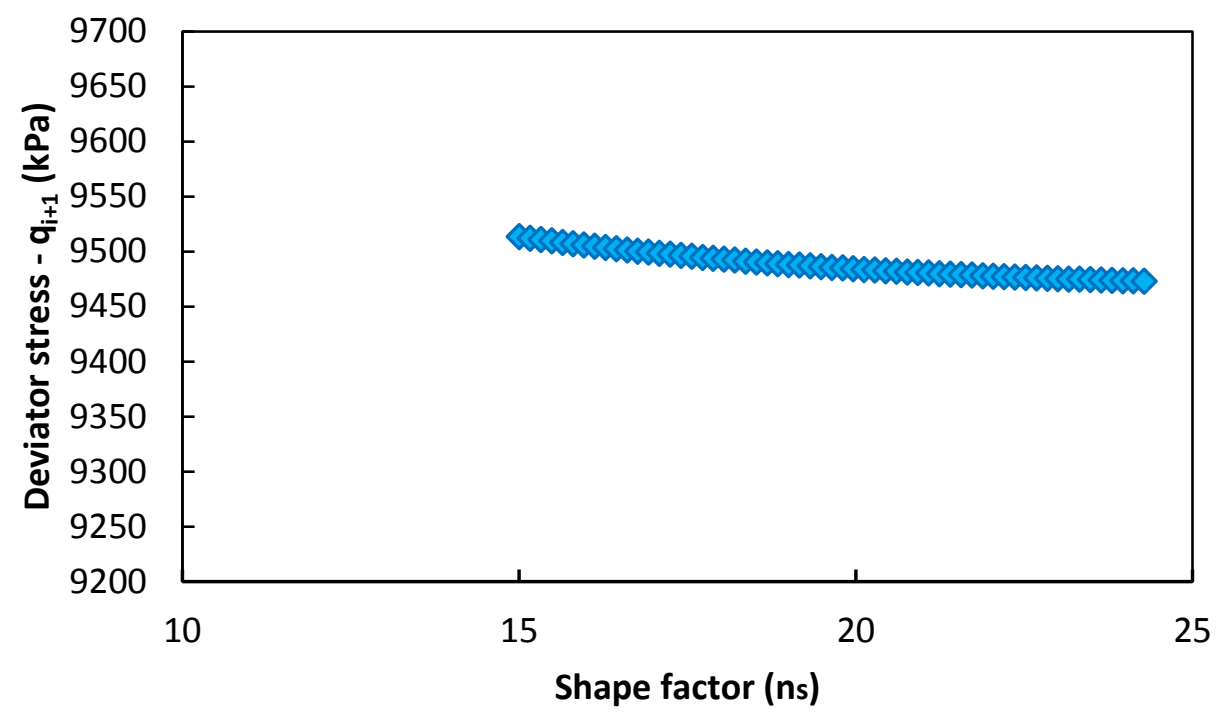

(a)

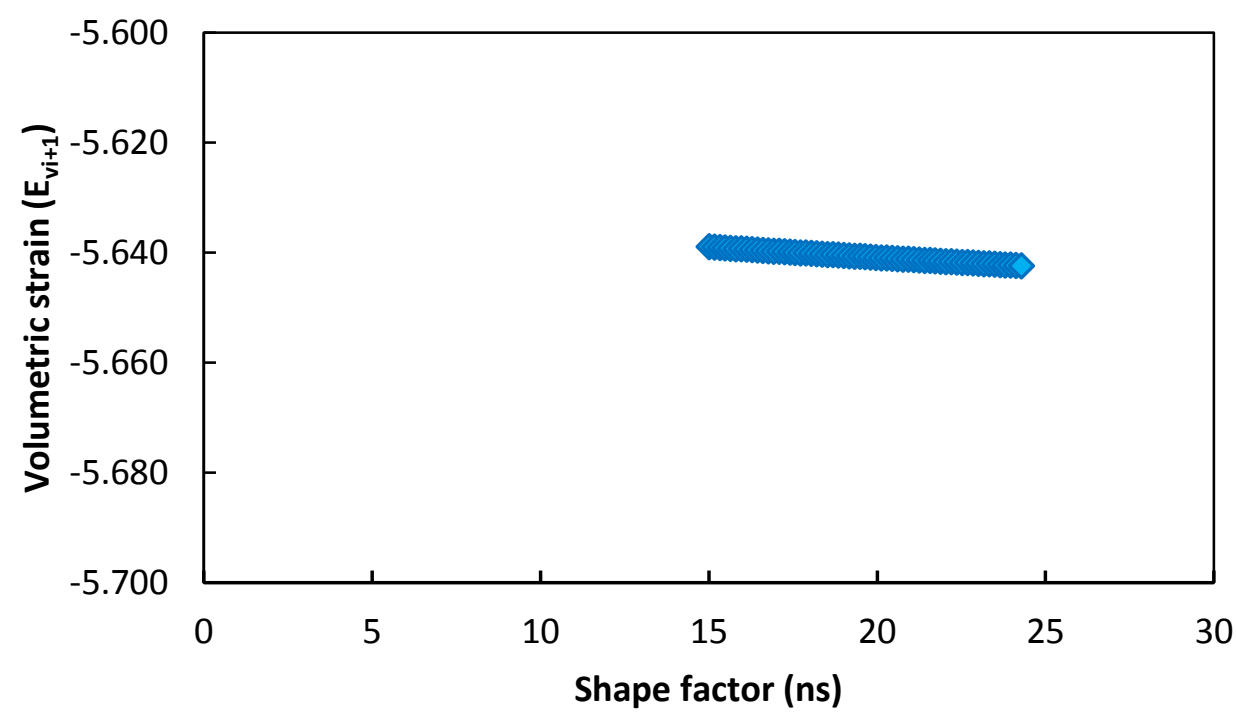

(b)

Figure 15: Sensitivity analysis results considering the effect of shape factor $\left(n_{s}\right)$ parameter on EPR model predictions for (a) deviator stress and (b) volumetric strain. 


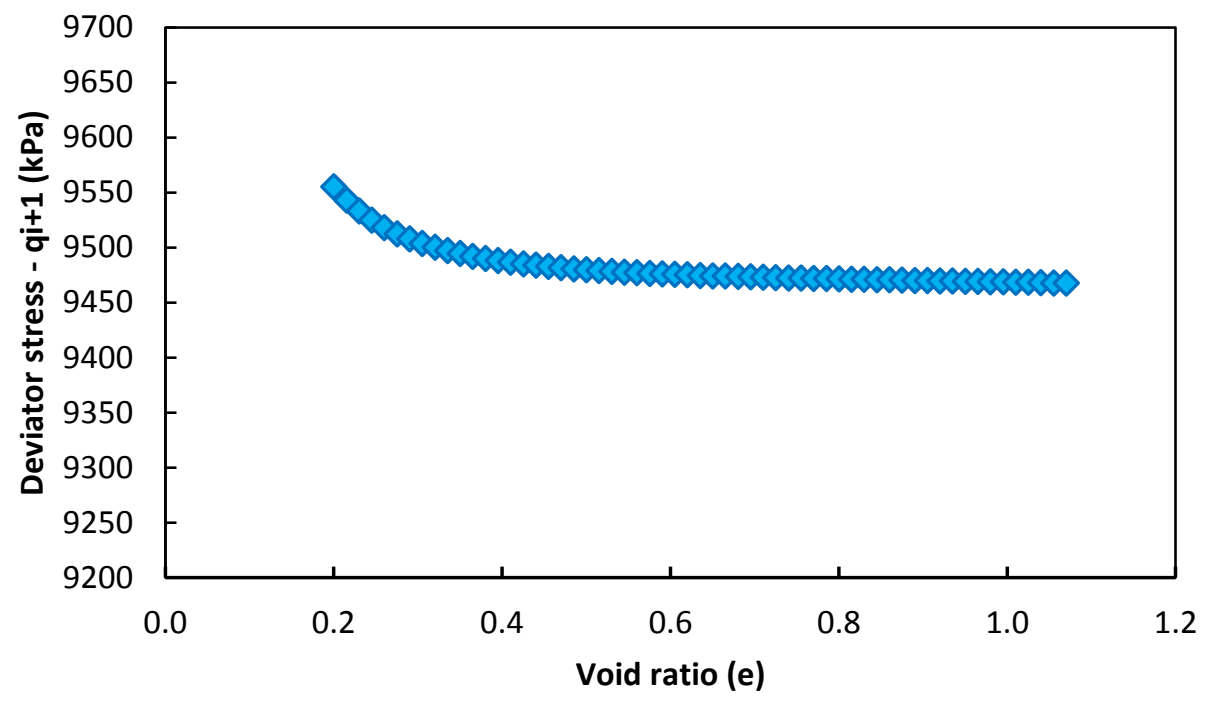

(a)

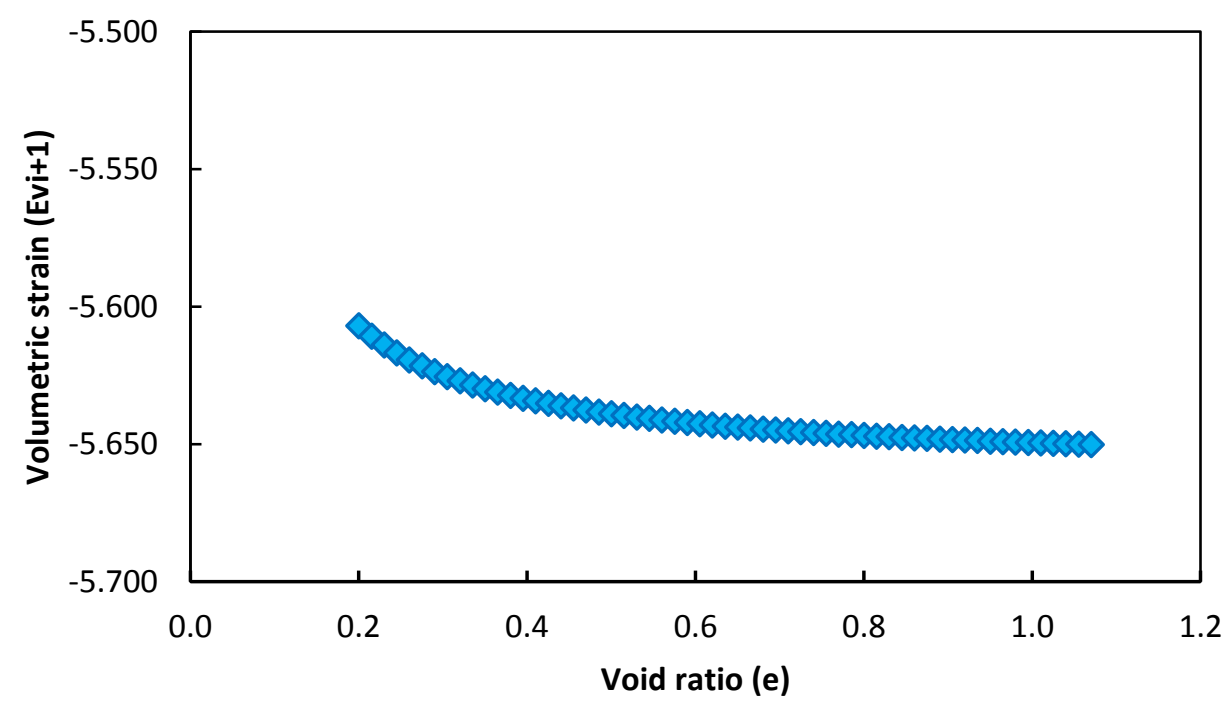

(b)

Figure 16: Sensitivity analysis results considering the effect of void ratio parameter (e) on EPR model predictions for (a) deviator stress and (b) volumetric strain. 
Table 1: Data sources used to create the database

\begin{tabular}{|c|c|}
\hline Reference & Experimental soil description \\
\hline Lee and Seed (1967) & Sacramento river sand \\
\hline Lee, Seed and Dunlop (1967) & Antioch sand \\
\hline Leslie (1975) & $\begin{array}{l}\text { Napa basalt } \\
\text { New Hogan metavolcanic } \\
\text { Carters Dam quartzite } \\
\text { Cougar basalt } \\
\text { Sonora dolomite } \\
\text { Laurel sandstone } \\
\text { Buchanan weathered granite }\end{array}$ \\
\hline Lo and Roy (1973) & $\begin{array}{l}\text { Back mine quartz sand } \\
\text { St. Marc limestone sand } \\
\text { Aluminum oxide sand }\end{array}$ \\
\hline Marachi et al (1969) & $\begin{array}{l}\text { Pyramid dam material } \\
\text { Napa basalt }\end{array}$ \\
\hline Miura and Yamanouchi (1975) & Toyoura sand \\
\hline Miura and O-Hara (1979) & Ube decomposed granite \\
\hline Ponce and Bell (1971) & Quartz sand \\
\hline Ramamurthy et al (1974) & Badarpur sand \\
\hline Raymond and Davies (1978) & $\begin{array}{l}\text { Coteau dolomite } \\
\text { Kenora granite } \\
\text { Nouvelle igneous } \\
\text { Sudburg slag }\end{array}$ \\
\hline Raymond and Diyaljee (1979) & $\begin{array}{l}\text { Grenville marble } \\
\text { Kimberly float } \\
\text { St. Isodore limestone } \\
\text { Brandon gravel } \\
\text { St. Bruno shale }\end{array}$ \\
\hline Wu (1957) & Fluvioglacial sand \\
\hline Erzin (2004) & Anatolian sands \\
\hline
\end{tabular}


Table 2: Parameters involved in the developed EPR models*

\begin{tabular}{cc}
\hline Contributing parameters & Model output \\
\hline $\mathrm{D}_{50}, \mathrm{C}_{\mathrm{u}}, \mathrm{C}_{\mathrm{c}}, \mathrm{h}, \mathrm{n}_{\mathrm{s}, \mathrm{e}, \sigma_{3}}$ & $q_{i+1}$ \\
$\varepsilon_{a}, \Delta \varepsilon_{a}, \mathrm{q}_{\mathrm{i}}, \varepsilon_{v, i}$ & $\varepsilon_{v, i+1}$ \\
\hline
\end{tabular}

* $\mathrm{D}_{50}(\mathrm{~mm})=$ average grain size, $\mathrm{Cu}=$ coefficient of uniformity, $\mathrm{C}_{\mathrm{c}}=$ coefficient of curvature; $\mathrm{h}=$ hardness of the mineral; $\varepsilon_{a}=$ axial strain; $\mathrm{n}_{\mathrm{s}}=$ shape factor; $\varepsilon_{v}=$ volumetric strain; $q=$ deviator stress; $\Delta \varepsilon_{a}=$ axial strain increment; $\mathrm{e}=$ void ratio; $\sigma_{3}=$ effective confining pressure.

Table 3: COD values for EPR models

\begin{tabular}{lcc}
\hline \multicolumn{1}{c}{ Equation } & $\begin{array}{c}\text { COD values for } \\
\text { training (\%) }\end{array}$ & $\begin{array}{c}\text { COD values for } \\
\text { testing (\%) }\end{array}$ \\
\hline Deviator stress (Equation 6) & 99.99 & 99.98 \\
Volumetric strain (Equation 7) & 99.99 & 99.99 \\
\hline
\end{tabular}

